\title{
Electrical-Based Diagnostic Techniques for Assessing Insulation Condition in Aged Transformers
}

\author{
Issouf Fofana * and Yazid Hadjadj \\ Research Chair on the Aging of Power Network Infrastructure (ViAHT), Université du Québec à Chicoutimi, \\ 555 Boulevard de l'université, Chicoutimi, QC G7H 2B1, Canada; yazid.hadjadj@uqac.ca \\ * Correspondence: ifofana@uqac.ca; Tel.: +1-418-545-5011
}

Academic Editor: Chunhua Liu

Received: 20 March 2016; Accepted: 8 August 2016; Published: 26 August 2016

\begin{abstract}
The condition of the internal cellulosic paper and oil insulation are of concern for the performance of power transformers. Over the years, a number of methods have been developed to diagnose and monitor the degradation/aging of the transformer internal insulation system. Some of this degradation/aging can be assessed from electrical responses. Currently there are a variety of electrical-based diagnostic techniques available for insulation condition monitoring of power transformers. In most cases, the electrical signals being monitored are due to mechanical or electric changes caused by physical changes in resistivity, inductance or capacitance, moisture, contamination or aging by-products in the insulation. This paper presents a description of commonly used and modern electrical-based diagnostic techniques along with their interpretation schemes.
\end{abstract}

Keywords: power transformers; diagnostic techniques; insulation condition; transformer aging; partial discharge (PD); return voltage (RV); dielectric response; dielectric dissipation factor (DDF); dielectric response analysis; mechanical or electrical integrity of the core and windings

\section{Introduction}

Power transformers, are indispensable components of power generation plants, transmission systems and large industrial plants. Composite oil/paper insulation systems have being used in these important machines for more than a century. Despite great strides in electrical equipment design in recent years, the Achilles heel in the equipment performance is still the insulation system. During service, the electrical insulation of transformer is subjected to several types of stresses (electrical, mechanical, thermal and environmental), some of them inter-related, occurring in different parts of the structure which degrade the insulation. As power transformers age, their internal insulation degrades, increasing the risk of failure. Insulation degradation/aging is recognized to be one of the major causes of transformer breakdown [1,2]. The weakest part the insulation system is the vulnerability to moisture content, oxygen, to excessive heat and mechanical stresses. When these elements are combined, the aging process is accelerated. When electrical equipment fails, more often than not, the fault can be traced back to defective insulation.

Since most installed power transformers are approaching the end of their design life, it is important to know, by means of suitable diagnostic tests, the condition of their insulation. Increasing requirements for appropriate tools allowing diagnosing power transformers non-destructively and reliably in the field have promoted the development of modern diagnostic techniques complementary to the classical insulation resistance (IR), power frequency dissipation factor (DF) and polarisation index measurements. During the last three decades, the understanding of oil-paper insulation degradation has significantly improved because of the development of several non-destructive techniques.

The life of the transformer being connected with that of its insulation, the evaluation of the transformer insulation is essential to assess the condition of the unit when new and after several years 
of in-use service. This evaluation necessarily involves both electrical and physicochemical techniques and diagnostic methods. It should be emphasized that it is very difficult to cover all those techniques in one paper. This review encompasses electrical-based diagnostic techniques for assessing insulation condition in aged transformers, while physicochemical-based diagnostic techniques are the concern of a companion paper published in this special issue [3]. Together with the physicochemical methods, the electrical-based diagnostic methods are very important for the condition monitoring or for studying the degradation of the insulation in power transformer.

In recent years, many research works have been undertaken to develop or improve the electrical-based diagnostic methods while the basic concept has stayed almost the same. Figure 1 summarizes the typical problems that may be detected with electrical-based test methods [2].

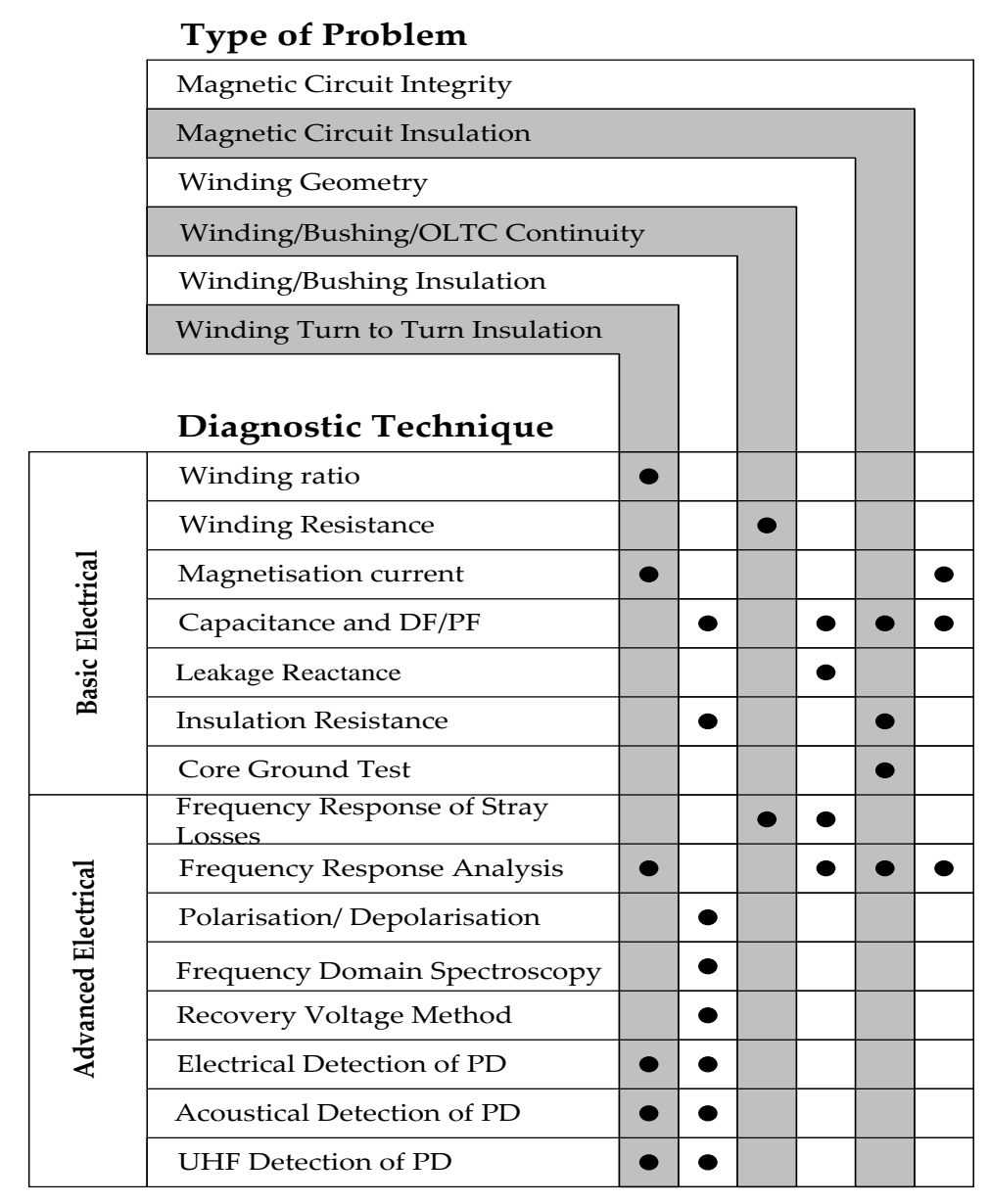

Figure 1. Electrical Tests Diagnostic Matrix, based on the one proposed in [2]. OLTC: on load tap changer; DF: dissipation factor, PF: power factor; PD: partial discharge; UHF: ultra high frequency.

\section{Traditional Electrical Diagnostic Techniques}

The dielectric dissipation factor (DDF) at power frequency and breakdown strengths at both power frequency and lightning impulse, have been the most often controlled parameter describing the oil-paper's function as an insulant. When the oil-paper insulation ages in a transformer, these parameters do not change drastically. Very little systematic research had therefore been undertaken for condition monitoring or for studying the degradation of electrical insulation in power transformers until 1990 [2]. 


\subsection{Breakdown Strength}

The Alternative Current (AC) electric strength, also known as breakdown voltage at power frequency, is one of the most controlled parameters describing the liquid's function as an insulant. This parameter is strongly sensitive to the following factors [4]:

- Chemical makeup of the fluid;

- Temperature;

- Amount of contamination (impurities, moisture, etc.);

- Sampling and preparation conditions;

The AC electric strength, therefore, serves primarily to indicate the presence of contaminants such as water or particles [2]. New, dry and clean insulating fluids exhibit breakdown voltages higher than $70 \mathrm{kV}$ for mineral oils, esters and $50 \mathrm{kV}$ for silicone fluids [5,6], which can be reduced dramatically when solid particles and free and/or dissolved water are present [7]. Most of the breakdown voltage specifications for in-service transformers require a minimum of $30 \mathrm{kV}$ with a $2.5 \mathrm{~mm}$ gap [8], when measured with disc electrodes. However, it should be emphasized that a high value does not necessarily indicate that the fluid is free of contaminants [4].

\subsection{Static Electrification and Flow Electrification}

Problems due to static electrification in power transformers have been reported by many utilities around the world since the 1970s $[9,10]$. The physicochemical process appearing at the oil-pressboard interface leads to an electrical double layer (EDL). This phenomenon is due to the formation of a EDL at the oil-pressboard interface [11].

Static electricity generation occurs in forced oil cooled power transformers due to the flows of oil through the surface of the pressboard. The flow of oil leads to charge separation at the oil-paper interfaces. During its motion, the oil acquires a positive or negative charge depending on the surface over which it travels $[12,13]$. If relaxation does not eliminate oil charges, and the charge accumulation at the insulating surfaces is high, static electrical fields can be produced, which may end in a static electrical discharge $[12,14]$. The combination of this static charge with impulse and switching surges may produce localized stresses of sufficient magnitude that they can initiate a catastrophic transformer failure [10]. The static charge is referred as static electrification but also known as flow or streaming electrification [9]. Many papers on flow electrification in transformers have been published to identify the various factors that influence this phenomenon. The most important ones are temperature, moisture, the oil flow rate, aging of oil, oil electrical charging tendency, and surface condition [10,15-18]. Some experimental measurements have reported that the overall flow electrification increases with temperature to a certain limit situated between $40^{\circ} \mathrm{C}$ and $60^{\circ} \mathrm{C}$ before decreasing [19]. Mas et al. [14], have shown that the temperature gradient influences the magnitude of the charge accumulated in the pressboard, but not the depth of the charge penetration. Oommen and Petrie [20], have reported that the electrostatic charge tendency of oil increases when the moisture content of the oil decreases. Studies have shown that the electrostatic charging tendency (ECT) increases as the oil flow increases [15]. It was reported also that the flow conditions-laminar or turbulent-also have a strong impact on the streaming current [21,22]. A direct relationship between ECT and aging was observed [23-25]. Sulfoxide compounds and hydrogen ions are identified as the prime compounds that increase ECT of mineral insulating oil [23]. In recent work, it was found that the dissolved decay products content and suspended particles are also contributing factors [26]. It was also demonstrated that the electrification current is affected by the quantity of free radicals present [27].

The influence of these parameters and the quantification of the charging tendency of insulating oil have been carried out by employing different experimental methodologies, developed in laboratories. One of the most commonly applied measurements is the mini static tester (MST) developed by Westinghouse Electric Corporation [28]. However, the MST protocol does not take into account a 
number of factors that can influence the ECT, such as the air and rate of injection [29]. This is why some modifications have been made by different authors to improve the accuracy of the protocol and ensure the reproducibility of measurements [30]. Other devices have been developed using a Couette charging apparatus where the fluid fills the Couette device consisting of rotating coaxial cylinders. The metal cylinder walls can be covered with insulating paper [16,31]. Kedzia [32] introduced an alternative method for testing the electrification of transformer oil based on a spinning disk in the liquid. Due to the simple construction and the small volume of oil needed, this method was recommended in a modified form by CIGRE [33]. Other than mineral oil, studies of ester behavior versus electrostatic hazard due to flow electrification have shown that even if ester oils increase the charge generation in comparison with mineral oil, the charge accumulation on the solid surface is not excessive [34]. To prevent static electrification, certain countermeasures have been worked out. The insulator edges are rounded and duct structures are designed so as to suppress turbulence and direct blow up of oil flow into the coils. In addition, flow speeds are limited [35]. In Japan, a method of suppressing charging tendency by using benzotriazole (BTA) as an insulating oil additive was developed [36,37]. It was confirmed that BTA suppresses not only flow electrification, but also copper sulphide generation [38].

Actually, the measurement of the ECT in power transformers is still as important as fifteen years ago, when research on the problems of static electrification started. Since ECT affects volume resistivities, partial discharges (PDs) and dielectric losses, a capacitive sensor was recently proposed to assess power transformer behaviour towards flow electrification and electrostatic hazard. This capacitive sensor is intended for online monitoring of the flow electrification hazards in transformers [39].

\subsection{Capacitance and Dielectric Dissipation Factor (or Power Factor)}

This test method, and its result, may be variously referred to by many terms such as loss factor, loss angle, dielectric loss angle (DLA), tan $\delta$ or tangent delta, $\delta, \mathrm{DDF}, \mathrm{DF}$, power factor (PF), $\cos \phi$ or $\cos \theta$. PF measurements relate mainly to the bushings of transformers. The DDF indicates the dielectric loss or the leakage current associated with watts loss of oil; thus the dielectric heating. Transformers aging by-products are mostly polar in nature and will affect conductivity as well as permittivity and capacitance. Any decrease in the resistivity results in an increase in the DDF/PF. The DDF/PF and capacitance are useful as a means of quality control, and as an indication of changes in quality resulting from contamination, aging and deterioration in service (damaged or short-circuited foil) or as a result of handling. The capacitance tends to increase with insulation degradation, poor impregnation methods and change of the geometry between windings. Higher capacitance implies higher permittivity, and hence worse condition of the insulation. The capacitance and DDF are the most common techniques for assessing the bushing condition. This test is normally performed at $10 \mathrm{kV}$ for bushing on-site measurements. Bushings' capacitance and PF can also be monitored by measuring the leakage current through capacitance tap (where capacitance taps are available) [40,41].

The capacitance and DDF of a dielectric is a complex function of at least two variables-frequency and temperature, although moisture and pressure may be other physical variables. The test voltage characteristics and temperature must therefore be recorded. The DDF test results are to be compared to nameplate values or previous tests. An increase or decrease from reference values is an indication of the presence of [2]:

- contamination products such as moisture, carbon or other conducting matter, metal soaps caused by acids attacking transformer metals and oxidation byproducts; or

- deterioration of the insulation system.

Acceptable limits depend largely upon the type of equipment. For in-service oils, the limit is less than $0.5 \%$ at $25{ }^{\circ} \mathrm{C}$ [42]. If the PF is greater than $0.5 \%$ and less than $1.0 \%$, further investigations are required; the oil may require treatment through three different processes (filtration, reclamation, reconditioning or re-refining [43]. If the $\mathrm{PF}$ is greater than $1.0 \%$ at $25^{\circ} \mathrm{C}$, the oil may cause failure of 
the transformer and immediate replacement or reclamation of the oil is required [44]. Above $2 \%$, the oil should be removed from service and replaced because equipment failure is imminent. This oil can no longer be reclaimed.

\subsection{Ratio and Winding Resistance Measurements}

These tests are part of the tests applicable to liquid-immersed distribution, power, and regulating transformers mentioned in the standard IEEE Std C57.12.90-2010 [45]. The ratio test determines the ratio of the number of turns in the high voltage (HV) winding to that in the low voltage (LV) winding [46]. This test is useful to verify whether or not there are any shorted turns or open winding circuits. The measured ratio is $0.5 \%$ of the ratio of the rated voltage between windings, as specified on the transformer nameplate [45-48]. There are three accepted methods for performing the ratio test: the voltmeter method, the comparison method, and the ratio bridge [46].

Transformer winding resistance measurements are of fundamental importance as they address the calculation of the winding conductor $I^{2} R$ losses, where $I$ is the rated current of the winding in amperes, and $R$ is the measured of Direct Current (DC) resistance of the winding [45]. This measurements is used also to determine the average winding temperatures at the end of a temperature rise test [45]. Because winding resistance varies with conductor temperature, from the change in resistance, the change in temperature can be deduced [49]. The winding resistance measurements are used as type test as well as routine test. It is also employed as base for assessing possible damage, including contact problems on the tap selector, contact problems on the diverter switch, broken conductors, broken parallel strands, shorted winding disks, shorted winding layers, poor bushing connections [2]. For subsequent comparison, the measurement temperature should be recorded and the resistance converted to a reference temperature. A variation of more than 5\% may indicate winding damage [47]. The transformer winding resistances can be measured either by the voltmeter-ammeter method or the bridge method [45]. The IEEE Std C57.12.90 standard indicates that the bridge method is to be used in the cases where the rated current of the transformer winding is less than $1 \mathrm{~A}$, while the voltmeter-ammeter one is employed when the rated current of the transformer winding is $1 \mathrm{~A}$ or more [48].

\subsection{Insulation Resistance, Polarisation Index and Core Ground Tests}

IR is one of the traditional methods used to determine the transformer insulation deterioration, dryness or failures in the windings or core earthing. A high DC voltage (typical values are $1 \mathrm{kV}$ up to $5 \mathrm{kV}$ ) is applied to the winding under test. The leakage current is measured and the IR calculated and indicated by the instrument. A guard ring electrode is recommended in IR measurements to avoid influence of unwanted leakages.

In a dry/less contaminated transformer, the resistive leakage current is small and constant. In poor insulation, the resistive leakage current which consists of four different components (conductance, capacitance, absorption and surface leakage, each of which adds up to a composite response) may be quite large and may increase with time. IR profiles of healthy insulation systems appear as an inverse exponential function in form because of the four primary components of the current, two of them decrease exponentially. The measurements are performed at 1, 2, 5, 50 and $100 \mathrm{~min}$. If two successive measurements give the same results, the test may be stopped, and the values used to calculate the IR. Otherwise, the IR is reported as function of the electrification time. IR values have to be compared with values from previous measurements on the same unit or a sister unit in order to evaluate the actual condition of the insulation. Otherwise, bushing surfaces must be well cleaned before commencing the measurements. IR is a temperature-dependent test and not reliable enough in identifying partially wet insulation [2]. Unlike conductors where the resistance increases with temperature, IR is inversely proportional to temperature so IR decreases with temperature.

Another way of applying this testing is to use the polarization index (PI), a variation of the IR test by measuring the current after 1 and $10 \mathrm{~min}$ of voltage application. The PI index is the ratio of 
the IR measured after voltage has been applied for $10 \mathrm{~min}$ (R10), to the IR measured after just one minute (R1). This index, independent from temperature, was introduced to detect contaminated or wet rotating machines winding insulation. The IR and PI have been used by the electricity utilities for a long time to ascertain the transformer moisture condition [2]. In the last decades, field and laboratory investigations have revealed that for the complex oil-cellulose insulation system, the PI results can be misinterpreted [49,50]. Recall that the resistive leakage current is affected in different ways by the presence of moisture, contamination, temperature, and the insulation condition itself [51,52]. Field measurements are generally performed just after de-energising the transformer. Thus at onsite measurements, water migration is commonly occurring, the transformer is in a non-equilibrium state. Under such circumstances, large thermal variations may affect the results, since moisture distribution inside the insulation is not in complete equilibrium condition. Therefore PI is not considered as a good indicator for the state of the oil impregnated insulation condition, but the resistance itself is [50,51]. Dielectric response analyses are preferred for quantitative assessments of moisture in the insulation.

Power transformers are usually supplied with a ground from the core to the tank (earth/ground) to divert high potentials induced into the core safely to ground. The core ground also provides a low-resistance path to ground if there is a short circuit between the winding and the core, allowing protective relaying to detect it [53].

The core ground test is performed by disconnecting the core grounding outside the tank and the IR of the core to ground measured. This test is performed as a routine maintenance task to detect if the core has shifted, making contact with its tank, but usually performed when a transformer is first installed, moved or if a problem is indicated by dissolved gas analysis (DGA) with an increase in the combustible gases $[2,54]$. These gases are created by heat within the core produced by circulating currents. Typical values are in the order of $10 \mathrm{M} \Omega$ or higher. Values lower than $100 \mathrm{k} \Omega$ can indicate core grounding problems [2]. In some cases resistances (normally in the order of several $\mathrm{k} \Omega$ ) are used to ground separated core lamination packets.

Measurements of the core ground current in service show values in the order of some $\mathrm{mA}$ for a well-insulated core; if the core has grounding faults, the current is several amps or even higher [2].

\subsection{Leakage Reactance and Magnetising Current}

The leakage reactance of transformer is the consequence of the leakage flux in transformer. This self-reactance associated with resistance is the impedance of transformer which may induce voltage drops in both primary and secondary transformer windings. This test is performed to detect windings deformation following current faults, high inrush currents, Buchholz relay tripping, and protective relay tripping [2].

An AC source (preferable with variable frequency) connected to each phase of the HV winding with the corresponding LV winding short circuited, is required for measuring the leakage reactance. The leakage impedance is then determined from the measured current and the voltage across the HV winding. The measured value should be within $\pm 2 \%$ compared to the factory test report. This is because the difference between phases is usually less than 2\% [2]. Any changes higher than $1 \%$ should be further investigated with other tests such as frequency response analysis (FRA). Care is recommended when comparing three phase and one phase test measurements.

The magnetising current is the current which flows in the primary winding when an AC source is connected to each phase of the HV windings with the secondary windings unloaded. The voltage across the HV winding and the magnetising current are measured along with the phase angle if possible. The test voltage can be connected to the LV windings, but in this case the values have to be corrected using the square of the winding ratio. This test is performed to detect core faults (shorted laminations), shorted turns or winding parts.

Some test equipment may allow winding ratio to be measured concurrently. In this condition, the magnetising current measurement should be performed before winding resistance tests since, the residual flux could impact the measurement. 
The measured value at rated voltage should be within $0.1 \%-0.3 \%$ of rated current. Normally, the outer phases have similar values within $5 \%$. The current on the middle phase can be up to $30 \%$ lower [2]. Since this is a voltage-dependent test, the same test voltage and tap position should be used for comparison.

\section{Advanced Electrical Diagnostic Techniques}

To meet the pressing needs of the power industry advanced maintenance technologies/tools are necessary. In recent years new diagnostic methods complementary to the classical IR, power frequency DF and polarisation index measurements have been promoted. Some of these modern diagnostic methods include PDs detection, dielectric spectroscopic techniques, sweep frequency response analysis (SFRA), etc. Contrary to the basic electrical techniques (IR, PI, DDF, etc.), dielectric response measurements provide sufficient information about the condition of insulation, which is necessary for a reliable condition assessment. These methods are now available as user-friendly methods, and can be used to monitor, diagnose and check new insulating materials, qualification of insulating systems during/after production of power transformer non-destructively.

\subsection{Partial Discharge Detection Techniques}

PD is an electrical phenomenon that occurs inside a transformer and the magnitude of such discharges can cause progressive deterioration and sometime may lead to insulation failure. There are vast numbers of papers available on PD processes, PD patterns and fault mechanisms and are beyond the scope of this paper. A number of researchers have worked on the measurement of dielectric strength of pressboard and paper with different wave shapes power frequency or lightning impulse or switching impulse or combinations of these.

A PD is defined as a localized dielectric breakdown of a small portion of the electrical insulation, without completely bridging the conductors [55]. PD can be initiated by voids, cracks or inclusions within solid dielectric, at interfaces within solid or liquid dielectrics, in bubbles within liquid dielectrics or along boundaries between different insulation materials. PD deteriorate progressively the insulation and can lead to electrical breakdown which ultimately leads to equipment damage and can cause a considerable economic losses [56]. The affected component needs to be closely analysed to make sure the PD will not lead to further damage or even complete destruction. Therefore, the integrity of the insulation of HV equipment should be confirmed using PD analysis during its manufacturing, its commissioning and during its lifetime. In transformers, some PD sources include gas bubbles in the oil, voids in solid insulation material or floating metallic particles. The long term effect of PD on insulating systems is destructive, leading to the insulation deterioration or breakdown of power transformers $[47,57]$. PD activity in power transformers is often measured during factory acceptance testing using the conventional measurement according to IEC 60270 [55]. Depending on the voltage and the size of the transformer, the acceptable limits of PD for new transformers are in the range $<100 \mathrm{pC}$ to $<500 \mathrm{pC}$ [46]. Early detection and localization of PD is of utmost importance, it facilitates preventive repairs to avoid unforeseen breakdowns [56-58].

According to [59], PD can occur at difference locations within power transformer: core and coils assemlby, bushings, on load tap changer (OLTC), oil-barrier-paper structure and oil, etc. PD can be associated with operating voltage, voltage induced by main magnetic flux, voltage induced by stray flux. The source of PD can also be associated with switching processes, to reversible changes of insulation condition and to irreversible degradation of insulating materials.

An analysis of the root causes of transformer bushing failures following five incidents occurred at Jaalan Bani Bu (JBB) Ali Grid station on 2011, has been conducted by Feilat et al. [60]. Based on visual inspection of the failed bushings, comprehensive power quality measurements, frequency scan, and OLTC daily operations, they concluded that the failure could be attributed to internal localized insulation breakdown as indicated by the burn-through marks on the condenser paper and two melted spots on the HV central conductor. 
PD occurrence is usually followed by many electrical and chemical phenomena, such as current pulses characterised by short duration in the range of nanoseconds, electromagnetic radiations, ultrasonic waves, light, heat and gas pressure $[55,61,62]$. Based on the types of signals generated by PD, various sensing methods including electrical, acoustic, optical, electromagnetic and chemical methods have been proposed for detection and localization of PD in power transformers $[61,63]$.

\subsubsection{Electrical Detection of PDs}

The electrical methods used for detection of PD are based on the electrical phenomena accompanying the discharge such as electromagnetic radiation and electric current pulses. Therefore, two electrical-based detection methods can be distinguished: conventional PD measurement and the ultra-high frequency (UHF) methods [56]. The conventional electrical method consists in coupling sensors and a data acquisition system. In transformers, capacitive and inductive coupling sensors are generally used. The bushing tap of the transformer is used as a capacitive coupling sensor, while the current is measured by mean of high frequency current transformer (HFCT) which is an inductive coupling sensor $[56,61,63-66]$. The electrical measurements are very accurate and can provide information about the PD intensity, and possible determination of the defect type. However, as the power transformer environment contain high levels of electrical noise, in online electrical PD system, it is very hard to distinguish between noise and PD [67]. In such cases, offline measurements can be performed in order to eliminate some of noise, but this can lead to lost revenue for the power company. The conventional measurements, according to IEC 60270 is an approved PD measurements and is often used in power transformers during factory acceptance testing. The conventional method uses apparent charge, measured in $\mathrm{pC}$, which represents the integrated current pulse caused by a PD.

The PD pulse current has a short rise time, and radiates magnetic waves with frequencies up to the ultra-high range, therefore, the electromagnetic wave generated by PD has a frequency component in the UHF band. As the PD pulses propagate through the winding of transformer, they undergo a significant distortion and attenuation. To achieve an appropriate sensitivity in analyzing at what portion of the transformer the PD can be detected, an appropriate bandwidth can be used [65].

UHF sensors are able to detect the electromagnetic waves generated by PD, generally in the bandwidth range from $300 \mathrm{MHz}$ to $3 \mathrm{GHz}[56,61]$. In this frequency range and due to the shielding characteristic of the transformer tank, this method is less sensitive to the external interference compared to the electrical method [67-72]. However, the geometry inside the transformer acts as a waveguide in the UHF range and highly affects reflections and standing of UHF signals. It is therefore necessary to recalibrate UHF sensors for each transformer design [67]. Another issue is that, there is no standardized sensitivity check procedure for UHF sensors used for power transformers. The only methods established is based on the CIGRE recommendation transfer function (TF) 15/33.03.05 [68] for gas-insulated switchgear (GIS). The CIGRE method for GIS links the conventional PD measurements according to IEC 60270 in $\mathrm{pC}$ to UHF measurements. However, no correlation between the conventional PD measuring method $(\mathrm{pC})$ and the UHF signals $(\mathrm{mV})$ for power transformers has yet been established [73].

The phenomenon of UHF signal attenuation within power transformers, due to the influence of the internal structure (windings, cores, field deflections etc.) on the propagation of UHF signals has been investigated [73,74]. For a reliable measurement several UHF antenna are used around the transformer tank using oil valves [75]. The PD location is usually detected using acoustic probes. However, the propagation times measured in the UHF range have been investigated for geometrical location of PD [76,77]. According to Coenen and Tenbohlen [76], the accuracy seems to be adequate to determine the phase limb where the PD is located, but additional acoustic measurement are always needed.

\subsubsection{Acoustical and Optical Detection of PDs}

Acoustic signals that occur during the PD event, can be captured using acoustic sensors such as piezoelectric transducers as well as fiber optic acoustic sensors, accelerometers, condenser microphones 
and sound-resonance sensors [61]. This acoustic signal is created by the explosion of mechanical energy caused by vaporisation of material around the hot streamer within the void. This energy propagates through the transformer tank in the form of a pressure field [78-81]. The benefit of acoustic methods is the ability to localize PD sources using multiple sensors in different positions on the transformer tank [79,81-84]. One of the common methods used to localize the PD is the so called arrival time analysis [83]. Acoustic waves are actually strongly influenced by the geometry of transformer as well as by the insulation medium [85]. This leads to a change in the sound propagation, resulting in damping, absorption and scattering effects on the measurable acoustic compression. PD localization can help plant technicians locate faults in insulation for repair purposes. Consequently, many researchers have proposed different algorithms allowing precisely localization of the PD locations in transformers $[82,84,86,87]$. Potential for the on-line detection of PDs of a new generation of piezoelectric sensors (high temperature ultrasonic transducers, (HTUTs)) is reported by Danouj et al. [88]. An advantage of acoustic methods is their immunity to electromagnetic interference which makes them suitable for online real-time applications [56,61]. However, acoustic sensors also have some limitations, as they are less sensitive compared to electrical signal methods, due to the attenuation mechanisms inside the transformer [78].

Fiber-optic acoustic sensors have been developed to increase the sensitivity of acoustic signals detection [89-92]. Actually, the fiber sensor uses an optical signal to measure acoustic signals. Unlike the acoustic sensors that are placed on the tank of the transformer, the optical fiber sensor can be placed inside the transformer. The main advantages of this method are the immunity from electromagnetic interferences, high sensitivity, the ability to with stand high temperatures, large bandwidth and resistance to chemical corrosion. However, their major disadvantage are the high cost and end-user unfamiliarity [93]. The detection process of this method is based on the change of the optical fiber length and refraction index caused by acoustic waves [64]. The acoustic wave in the transformer oil can be detected using an optical fibre acoustic sensor. This sensor is made up by bonding silica tubing and silica diaphragm together to form a sealed fibre optic extrinsic Fabry-Perot interferometer. The acoustic wave induces a dynamic pressure on the diaphragm which lead to the vibration of the diaphragm. Therefore, it is very important to design the sensor head to ensure high enough frequency response and sensitivity to achieve optimum detection of PDs [92].

\subsubsection{Chemical Detection of PDs}

DGA using gas chromatography is one of the most sensitive and reliable techniques used for assessing the condition of oil-filled transformers. Under electrical and thermal stresses, small quantities of gases may be liberated due to decomposition of oil and cellulose insulation. The quantity and composition of the liberated gases depends on the type of fault [94]. The distribution of these gases can help identifying different types of PD using standard interpretation methods $[95,96]$.

The other method which is used for PD detection is the high performance liquid chromatography (HPLC) method. The HPLC test measures the glucose by-product produced due to the cellulose insulation breakdown [61]. The disadvantages of chemical detection is that both methods take too much time between the collection of sufficient quantities of gases or by-products and the initiation of PD source to be detected. This mean that chemical methods cannot be used for real-time and online monitoring [61]. Furthermore, chemical methods are not able to provide information about the position of the PD source or the extent of insulation damage. Unfortunately, there is no calibration standard between chemical methods and apparent charge. As a consequence the chemical methods are used to verify the presence of errors [85]. One of the most important phenomena that can lead to initiation of PD is the accumulation of the electrostatic charge. It is very important to study and understand how this can occur to avoid catastrophic failures. 


\subsection{Frequency Response Analysis}

FRA is a powerful tool in advanced power transformer assessments to evaluate the mechanical or electrical integrity of the core and windings by measuring the electrical transfer functions over a wide frequency range. The results can be compared to the outcomes of traditional tests such as transformer turn ratio (TTR), winding resistance or leakage reactance. International standardization and research entities have approved two standards and two guides on SFRA testing [97-100].

This technique is sensitive to changes in the configuration of transformer windings, because any changes in the winding geometry affect the internal winding inductance and capacitance, and consequently the relevant characteristic frequencies. This test is performed to detect windings deformation/displacement, shorted turns, core faults, faulty core grounding, faulty screen connections, and damage during transportation, etc.

FRA is a comparative method, that evaluates the transformer condition by comparing the obtained set of results to reference results on the same, or a similar unit [101-103]. Two testing procedures are available [2]:

(1) SFRA consisting in connecting a sinusoidal AC voltage with variable frequency (several $\mathrm{Hz}$ to several $\mathrm{MHz}$ ) to each phase of the $\mathrm{HV}$ and the $\mathrm{LV}$ windings with all other windings unloaded. The input voltage $\left(U_{\text {in }}\right)$ and the output voltage $\left(U_{\text {out }}\right)$ are measured at different frequencies.

(2) Impulse frequency response analysis (IFRA) consisting in injecting an impulse to each phase of the $\mathrm{HV}$ and the LV windings with all other windings unloaded. The input and output impulse curves of the windings are recorded. The time domain results are transformed into the frequency domain by using fast Fourier transform (FFT) algorithms. The $U_{\text {in }}$ and the $U_{\text {out }}$ are calculated for different frequencies.

For both methods, the ratio " $20 \log \left(U_{\text {out }} / U_{\text {in }}\right)$ " (in $\left.\mathrm{dB}\right)$ is calculated for each frequency and the results are plotted on a trace. Both methods give satisfactory results, but the IFRA does not give results in the low frequency range (below $1 \mathrm{kHz}$ ) [2]. The measurements can record a unique "fingerprint" of a transformer which can be compared to a previous measurement. The differences between them indicate that mechanical and electrical changes that have occurred inside the transformer. For each fault, the transfer impedance or TF is measured and compared to the original frequency response without defects. However, interpretations of frequency responses remain very vague and do not precisely locate emerging faults.

Care should be taken when interpreting FRA spectra. The total capacitance variations due to the temperature and moisture changes in the test objects can lead to misinterpretation. Statistical indices in FRA evaluation were proposed to explore their capability in FRA spectrum interpretation once the moisture content of paper insulation is changed [104].

Another important fundamental shortcoming related to this technique is the fault discrimination and location. Using rational function based on vector fitting (VF) approaches, index, and synthesized zeros/poles are introduced to specify the type, level and location of the fault in the winding [105-107]. Results presented demonstrate the feasibility of the approaches.

The FRA test is valuable when the result is compared to a baseline measurement performed under similar conditions to guarantee repeatability of the results; however, as per the inherent characteristics of the FRA test, repeatability can be easily compromised [98-100].

One of the main concerns with SFRA is its limitation to offline testing since the method requires injection of a test signal into the transformer windings through the high-voltage bushings. Behjat et al. [108] investigated the feasibility for online transfer function monitoring of the power transformers windings through a quite simple, economic, and noninvasive capacitive sensor installed on the surface of the transformer bushing is presented. 


\subsection{Dielectric Response Analysis}

The fundamental theories behind dielectric measurements were first developed by Jonscher [109] but was never used as a diagnostic tool. Only recently [110], that is to say, during the last two decades, extensive research was centered to this diagnostic technology. The insulation system of power transformers consists of oil and cellulose, whose dielectric properties are strongly influenced by moisture, temperature and aging. Their condition can therefore, be evaluated using dielectric response measurements. Indeed, the dielectric response, which is a unique characteristic of the particular insulation system, can provide indication into aging and moisture content of the transformer insulation [111]. There are three methods referred to dielectric response analysis (DRA) [51,110-134]:

(1) Recovery voltage measurement (RVM), sometimes also called return voltage (RV) measurement;

(2) Polarization and depolarisation current (PDC);

(3) Frequency domain spectroscopy (FDS).

All these methods reflect the same fundamental polarization and conduction phenomena [113], they are available as portable user-friendly methods, and can be used to monitor, diagnose and check new insulating materials, qualification of insulating systems during/after production of power equipment non-destructively. Material properties and geometry must also be taken into account when moisture in the solid insulation is to be derived from any of these three methods. These techniques are global methods, i.e., each test object is regarded as a "black box" accessible only by its electric terminals. Therefore, only global changes of the insulation can be identified but not localized defects [113]. Sophisticated analysis methods [51,110-115] can determine the water content of cellulose (paper/pressboard).

\subsubsection{Polarization and Depolarization Current}

The measurement of PDC following a DC voltage step allows investigating slow polarization processes [110]. Before PDC measurements, the dielectric memory of the test object must be cleared. A ripple- and noise-free DC voltage source is required to record the small polarization current with sufficient accuracy. The procedure consists in applying a DC charging voltage to the test object for a long time. During this time, the polarization current through the test object arising from the activation of the polarization process with different time constants corresponding to different insulation materials and to the conductivity of the object, which has been previously carefully discharged is measured. The voltage is then removed and the object short-circuited, enabling the measurement of the depolarization current (or discharging, or desorption) in the opposite direction, without contribution of the conductivity. In both cases (polarization and depolarisation), a long charging time is required (generally 10,000 s) in order to assess the interfacial polarization and paper condition [51,110-115].

The prevailing method of representation consists in plotting the relaxation measurement results in a $\log / \log$ scale with charging and discharging current of $t=10^{4} \mathrm{~s}$ (Figure 2). The interpretation scheme allows a separation between influences of moisture in solid insulation and other influences (e.g., oil conductivity). According to this common interpretation scheme, the first 1-100 s are influenced by oil conductivity. The end value of polarisation current is determined by the pressboard resistance and therefore by moisture. Initial values of the polarization current are related to the oil conductivity while the transient current variation is determined by geometry and oil properties. 


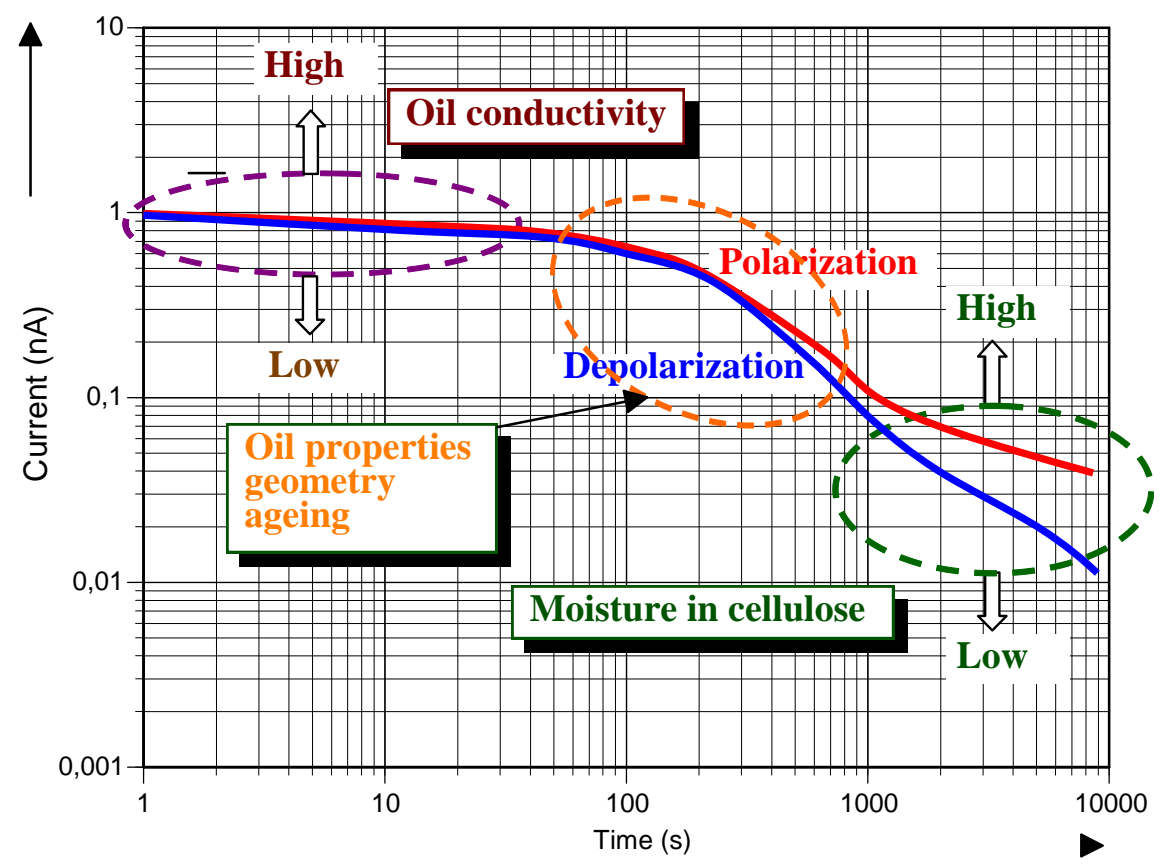

Figure 2. Interpretation of PDC measurement data.

\subsubsection{Recovery Voltage Method}

The recovery voltage method is another method in the time domain to investigate slow polarisation processes. This technique for the on-site measurement of the bulk dielectric properties for power transformers appeared about three decades ago [111]. The insulation condition can be physically monitored by various parameters of RV measurement, including the maximum peak voltage, central time constant and the initial slope of the RV curve [2,111].

This offline non-destructive diagnostic technique consists in applying a DC voltage $U_{\mathrm{c}}$ over the electrodes of a completely discharged test object. Typically, a DC voltage between 0.5 and $2 \mathrm{kV}$ is applied to the test object. During the charging period $T_{\mathrm{d}}$, the polarisation current $I_{\text {pol }}(t)$ flows through the test object. Following this period, the test object is short-circuited (grounded) and the depolarisation current $I_{\text {depol }}(t)$ flows. Both currents are, however, not measured. After a defined discharging period $T_{d}$, a recovery voltage, $U_{R}(t)$ is measured while the DC source is disconnected. After the short-circuiting (grounding) period is finished, the charge bounded by the polarization will turn into free charges i.e., a voltage will build up between the electrodes on the dielectric [121]. The RV is measured under opened circuit conditions (Figure 3). The sequence of RVM is repeated sequentially for charging time $T_{\mathrm{c}}$ for values varying from $1 \mathrm{~s}$ to $1200 \mathrm{~s}$. The used ratio of charging and discharging time $\left(T_{\mathrm{c}} / T_{\mathrm{d}}\right)$ is 2 . The polarization spectrum is obtained by plotting the peak value of recovery voltage $\left(U_{\max }\right)$ as a function of the charging time $T_{\mathrm{c}}$. 


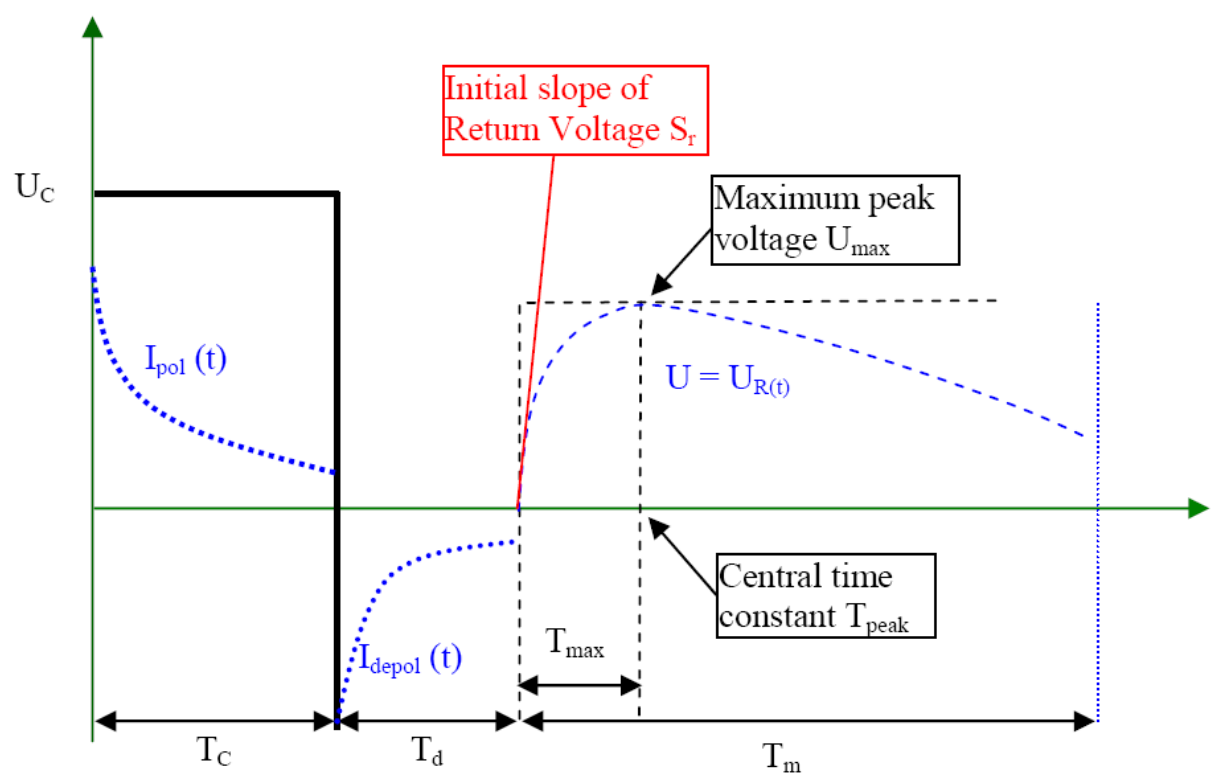

Figure 3. Schematic diagram of the recovery voltage measurement (RVM) process.

Interpretation of RVM results is usually based on the magnitude and the position of global maximum of the recovery voltage curve. As aging duration increases, the maximum of recovery voltage increases too. The resulting curve, $U_{\max }$ as a function of $T_{\mathrm{c}}$, is called the polarisation spectrum. The initial derivative, $S r=\mathrm{d} U_{\mathrm{R}} / \mathrm{d} t$ of the recovery voltage is also found and can be plotted as a function of $T_{\mathrm{c}}$.

The interpretation scheme must allow separating between the influences of moisture in the cellulose and other influences (e.g., oil conductivity), which is possible with the common scheme for the PDC and FDS methods but not for the RVM. CIGRE Task Force 15.01.09 reported the interaction of different effects on the "polarisation spectrum", which is used to evaluate RV measurements. The "polarisation spectrum" and its "central time constant" is mainly a mirror of interfacial polarisation. It is believed that the RV and peak time spectra are more dependent on the moisture content of the insulation than the aging [112]. However, it has been reported by several researchers that RVM is a complex convolution of the individual effects of oil and paper and their moisture and aging conditions [116]. The moisture content of the solid insulation influences this "spectrum" too, but it can't be separated from oil conductivity [111]. The RVM curves therefore do not depict unambiguously the separation of aging and moisture impacts on oil impregnated paper insulation condition [2,111].

Consequently, an alternative interpretation was proposed, to resolve previous anomalous moisture determinations. The moisture content in the solid insulation is instead, estimated from the polarisation spectrum which is examined for evidence of any subsidiary maxima away from the dominant time constant. The so called "Guuinic signature" has been found a useful aid in this process, in particular for confirming that the dominant time constant corresponds to the oil peak (narrow "nose") and assessing if there is any sign of polarisation activity above the dominant time constant [111]. In the "Guuinic signature" plot (Figure 4), the initial slope $S_{r}$ is plotted against the maximum recovery voltage $U_{\max }$ [121]. The moisture content is then estimated from this corresponding time constant using the published calibration curves [121]. 


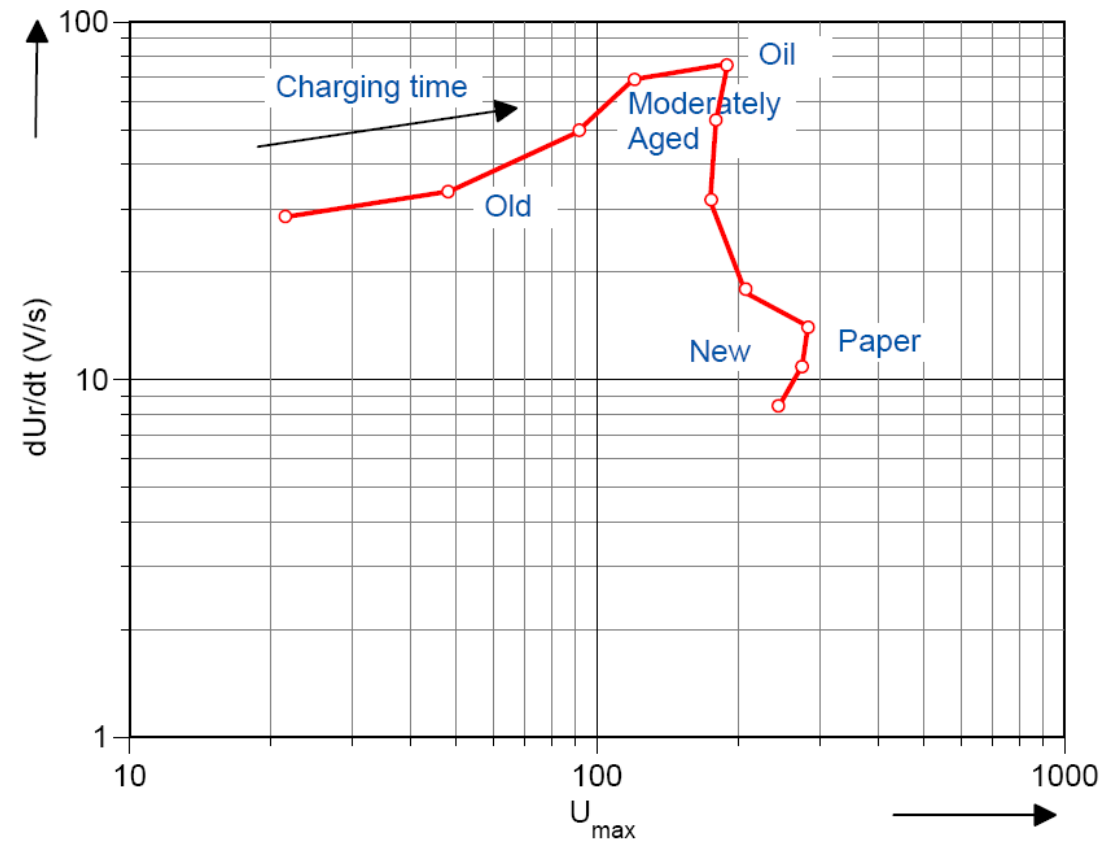

Figure 4. Guuinic representation [121].

According to this representation, while charging time $\mathrm{T}_{C}$ increases $S_{r}$ increases with $U_{\max }$. New paper depicts low $S r$ values for large values of $U_{\max }$, while aged insulation paper depict lower $S_{r}$ values at lower $U_{\max }$. Moderately aged paper exibits higher values of $S_{r}$ at moderate $U_{\max }$.

\subsubsection{Frequency Domain Spectroscopy}

The measurement principle is the same as capacitance and DDF/PF described previously but differs by being applied at different frequencies, typically from $0.001 \mathrm{~Hz}$ to $1000 \mathrm{~Hz}$.

The frequency response of the dielectric materials is being widely used as a diagnostic tool for insulation systems [51,110-119]. The monitoring of the complex permittivity and the DF of transformer insulation, as function of frequency provides inside information concerning the state of insulation within the components.

The relative complex permittivity $\left(\varepsilon_{\mathrm{r}}\right)$ is a dimensionless quantity, which compares the complex permittivity of a material $(\varepsilon)$ to the permittivity of the free space $\left(\varepsilon_{0}=8.854 \times 10^{-12} \mathrm{~F} / \mathrm{m}\right)$. It describes the interaction of a material with the electric field and consists of a real part $\varepsilon^{\prime}(\omega)$, which represents the storage, while the imaginary part of the complex relative permittivity, $\varepsilon^{\prime \prime}(\omega)$, (loss part) contains both the resistive (conduction) losses and the dielectric (polarisation) losses.

The behaviour of the complex relative permittivity when the resistive losses are dominant is that its imaginary part, $\varepsilon^{\prime \prime}(\omega)$, has a slope of $\omega^{-1}$ and the real part $\varepsilon^{\prime}(\omega)$ is constant [2]. It is therefore possible to determine the conductivity of the test object from the measured imaginary part of the complex relative permittivity.

The DDF (also known as $\tan \delta$, the ratio between the imaginary and real part of the complex relative permittivity) is a property of an electrical insulation system; low values of it are usually regarded as proof of good quality of the insulation. One practical advantage of the DDF is that it is independent of the test object geometry. The progressive increase of the DDF is closely related to the chemical degradation which accompanies aging/moistening of the insulation system.

When a sinusoidal voltage is applied across an insulation system, polarization processes start inside the insulation material resulting in a flow of current through it [109]. In the FDS techniques, the sample under test is subjected to sinusoidal voltage over a wide frequency range and the amplitude 
and phase of the response current flowing through the insulation are recorded from which, DF and complex capacitance are determined.

When the test object geometry is known, $\varepsilon^{\prime}(\omega)$ and $\varepsilon^{\prime \prime}(\omega)$, provide separately more information (conductivity $\sigma_{\mathrm{dc}}$, high-frequency component of the relative permittivity $\varepsilon \infty$, and dielectric susceptibility $\chi(\omega))$.

The moisture prediction is based on a model formulation which varies all insulation parameters (consisting of spacer, barrier and oil duct) to simulate every possible geometrical design. To make a precise moisture estimation of the oil-paper insulation in a transformer a library containing data on dielectric properties $\varepsilon \infty, \sigma_{\mathrm{dc}}$ and the dielectric function $f(t)$, of well characterised materials (oils and impregnated pressboard) at different humidity content is needed [111]. This information is needed for calculating the dielectric response of the composite duct insulation and for comparison with the results of the measurements. The software creates master curves and compares them to the measured DDF curve until the best possible match is reached. The Arrhenius equation is also applied to compensate for temperature dependence in the material. The final results are presented as a percent of moisture in paper and a separate value for oil conductivity.

The FDS measurement is carried out as a frequency sweep from $1 \mathrm{kHz}$ down till $0.1 \mathrm{mHz}$, thus causing unavoidable large measuring time due to the very low frequency oscillations. The prevailing method of representation consists in plotting the C-tan $\delta$ frequency scans in a log/log scale as depicted in Figure 5.

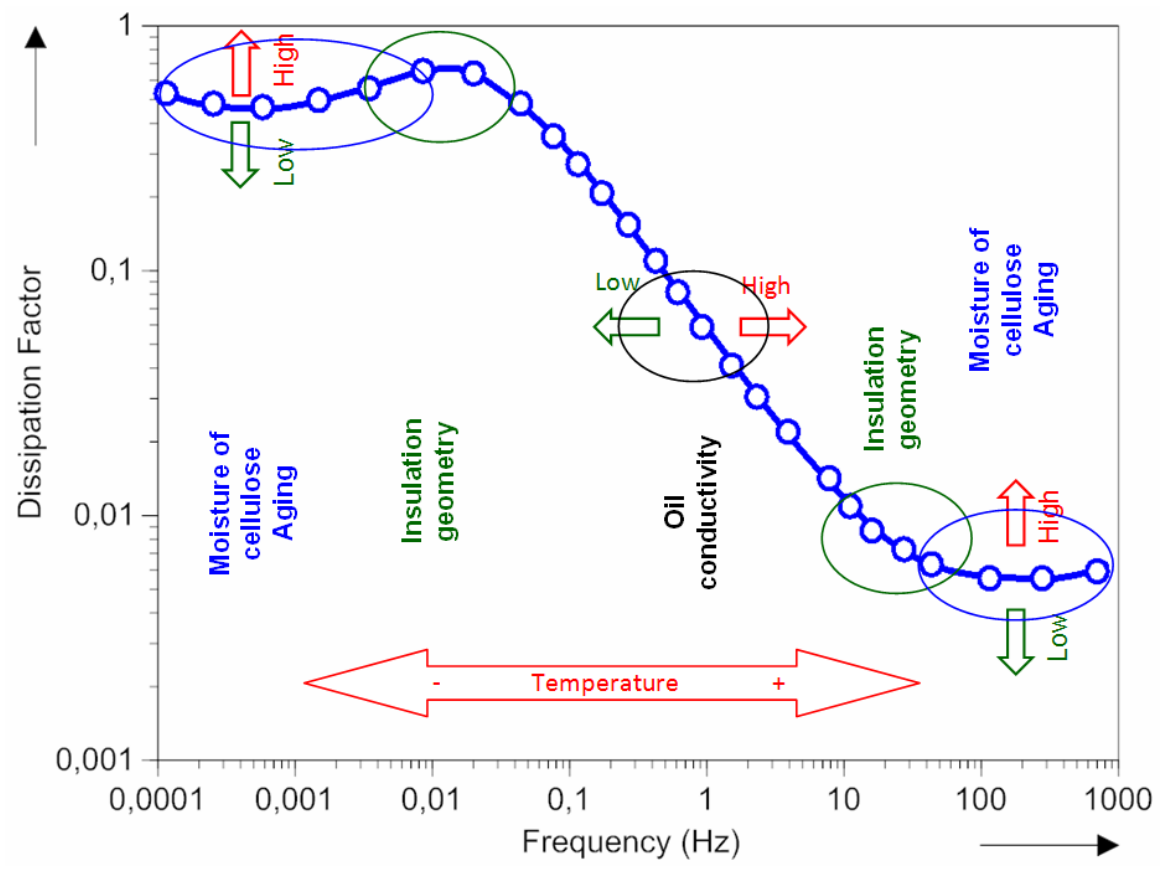

Figure 5. Separate impacts of oil conductivity and moisture in cellulose on frequency domain spectroscopy (FDS).

Different parts of the response, in frequency axis, are separately sensitive to properties of oil and solid parts of the insulation, as illustrated in Figure 5. At the very low frequency range $\left(<10^{-2} \mathrm{~Hz}\right)$ the response is mainly influenced by the condition of the cellulose. The same is true for the higher frequency range $(>10 \mathrm{~Hz})$. The central part of the response is, on the other hand, influenced by the properties of the oil, mainly by its conductivity [51,110-119].

A large number of papers have been published in this last decade to close some gaps in our understanding. Theoretical and experimental results have been reported in many contributions to demonstrate the effects of temperature, electric field, ageing and moisture content of paper and oil 
on the FDS results (e.g., [51,110-119]). It is now well accepted that FDS measurement techniques can provide indication onto aging and moisture content of the transformer insulation. However, Saha et al. [118] revealed that moisture content has a dominant influence on nearly all electrical based diagnostic techniques for assessing the condition of insulation, and indeed, masks their capability to determine the presence and extent of aging by-products of the insulation [121]. However, it must be emphasize that moisture and aging separation still constitute a challenging point in this domain.

Transformation of the results from time domain into the frequency domain has been an alternative that allowed reducing measurement duration (e.g., $[29,30])$. The time of measurement can be reduced to less than three hours in the lower frequency ranges. More recently, some authors $[125,126]$ have proposed an alternative testing techniques to reduce the measuring time by measuring multiple sinusoidal oscillations simultaneously. Digital Fourier transformation (DFT) is used to separate the individual oscillations in the frequency domain. The proposed alternative techniques allow reducing the measuring time by up to $73 \%$.

Another important aspect, reported by many researchers is the influence of several factors, including temperature, rain and electromagnetic disturbances together with transformer's volume/geometry on the FDS measurements [9,19,51,114-130]. Producing a FDS measure for insulation which does not require volume/geometry might therefore be very helpful. Hadjadj et al. [131] reported the feasibility of using poles to get rid of/encompass equipment volume effect. Attempts to separate moisture and aging have been reported in the last decades [131-134].

\subsubsection{PDC, RVM or FDS?}

Analysis of the PDC measurements can provide reliable information about the condition of transformer insulation. With sophisticated analysis methods, the PDC measurement can predict the moisture content in the solid insulation along the conductivities of the oil and paper. Other diagnostic quantities like $\tan \delta$, PI and polarization spectra can be calculated from PDC measurements directly.

Dielectric FDS enables measurements of the composite insulation capacitance, permittivity, conductivity (and resistivity) and loss factor in dependency of frequency. The real and imaginary part of the capacitance and permittivity can be separated. This non-destructive technique also provides the moisture content in the solid insulation material and C-ratio diagnostic quantity. The RVM technique has been criticised on various grounds [122,123]:

- moisture determinations, as derived by the evaluation method used, were often much higher than values obtained by other methods such as Karl Fisher titration;

- the recommended interpretation scheme is too simplistic;

- the technique does not take into account dependencies on geometry and oil properties.

It is also sometimes argued that it is easier to interpret data in the frequency domain than data in the time domain since the frequency data sometimes show nice features, like peaks [111]. A further comparison with PDC makes it clear, that while RVM is less noise-sensitive and simpler to set up on-site, the measuring results are sensitive to leakage currents due to the input impedance of the measuring instrument, polluted terminations, length and electrical characteristics of the connecting cable [128]. Furthermore the test duration is often longer and the RVM response depends critically on the charging and grounding duration [129]. Also the transformation of the RV measured data to the frequency domain is more difficult than those measured from PDC.

A brief comparison between Time Domain Method (TDM) and FDS techniques reveals that FDS has better noise performance and separates the behaviour of polarizability $\left(\chi^{\prime \prime}(\omega)\right)$ and losses $\left(\chi^{\prime}(\omega)\right)$ of a dielectric medium, while the dielectric response of an insulating system can be measured with the PDC method in shorter times and with a good accuracy [127]. All these methods appear to have their own strengths and weaknesses. As a result CIGRE Working Group Task Force 15.01.094 reviewed these polarisation techniques and concluded that although such techniques showed promise, more work are required to validate them and improve the interpretation of results [111]. Fields and 
laboratory investigations have revealed that moisture content has a dominant influence on nearly all electrical based diagnostic techniques for assessing the condition of insulation, and indeed, masks their capability to determine the presence and extent of aging by-products of the insulation [132]. According to Saha et al. [132], there are two main reasons why electrical techniques mostly do not provide good measures of the aging of insulation:

- the dominant effect of moisture on most electrical properties;

- the electrical properties of the oil impregnated paper and pressboard are probably more a complex function of oil and cellulose.

Therefore, electrical techniques may be not very sensitive to measure the extent of aging of paper/pressboard insulation. The interpretation of the DRA test results still remains a difficult task as it is believed to be influenced by various parameters including insulation ageing condition, moisture content, and insulation geometry/volume together with environmental condition such as temperature.

\section{Online Condition Monitoring and Diagnosis for Power Transformers}

Online condition monitoring of transformers is an essential element that helps to ensure the continuity and reliability of their operation. This therefore allows one to reduce costs and economic losses associated with their unavailability. Many tools to continuously monitor transformers are increasingly being used [135]. This is achieved by collecting data provided by a sensor setup [136]. A multitude of different measurable variables can be collected for on-line monitoring. For data acquisition, the sensors are connected to a monitoring module installed at the transformer, where the analogue signals are digitised before sending them to the monitoring server [136]. By means of advanced computational intelligence techniques, data are converted into useful information to correctly interpret various fault phenomena and accurately detect incipient faults [135]. Online monitoring systems show the capability to detect oncoming failures within active parts, bushings, on-load tap changers and cooling units [136]. However, active parts are considered the main aspects of transformer condition monitoring and assessment, including oil temperature and oil level, temperature of the ambient air and of the cooling medium, service voltage and current, over-voltages, dissolved gas, PD as far as measurable, tap changer position, torque movement of the OLTC motor drive, winding deformation and oil humidity which should be monitored closely in order to determine power transformer conditions, etc. $[135,136]$. Besides monitoring of the abovementioned quantities those sensors allow further monitoring functionalities with regard to the different components of a transformer as active parts, bushings, cooling units, etc. The Smart Grid concept represents an unprecedented opportunity to move the energy industry into a new era of reliability, where online monitoring is going to affect the future of power transformer diagnostics.

\section{Testing Suggestions/Recommendations}

To monitor transformer conditions, various test are required as addressed in this manuscript. The selection of some testing method depends on the nature of the defect or fault and the concerned component. CIGRE WG 12.18 have reported guidelines for recommendations and evaluations of tests and groups of tests for specific defects and faults. Table 1 summarises the corresponding tests in matrix format. Detailed recommendations can be found in the CIGRE WG 12.18 norms [137]. 
Table 1. Graphical suggestions/recommendations related to the nature of the defect or fault in power transformer's main component, adapted from [137]. Non-electrical-based techniques are in red. IR: insulation resistance; DDF: dielectric dissipation factor; DGA: dissolved gas analysis; IFT: Interfacial Tension; DRA: dielectric response analysis.

\begin{tabular}{|c|c|c|c|c|}
\hline \multirow{2}{*}{ Components } & \multicolumn{4}{|c|}{ Nature of the Defect or Fault } \\
\hline & Thermal (T) & Dielectric (D) & Mechanical (M) & Contamination or aging (C) \\
\hline Bushing (B) & $\begin{array}{ll}- & \mathrm{DDF} / \mathrm{PF} \\
- & \mathrm{DGA} \\
\text { - } & \text { Infrared thermal image tests }\end{array}$ & $\begin{array}{ll}- & \mathrm{DDF} / \mathrm{PF} \\
- & \mathrm{IR} \\
- & \mathrm{PD}\end{array}$ & $\begin{array}{ll}- & \text { Infrared (if external) } \\
\text { - } & \text { DGA (if internal) } \\
- & \text { Winding resistance }\end{array}$ & $\begin{array}{ll}\text { - } & \text { DDF/PF } \\
\text { - } & \text { PD } \\
\text { - } & \text { IR } \\
\text { - } & \text { DGA } \\
\text { - } & \text { Visual } \\
\text { - } & \text { Water content } \\
\text { - } & \text { Oil tests }\end{array}$ \\
\hline Core $(\mathrm{C})$ & $\begin{array}{ll}- & \text { Magnetizing current } \\
- & \text { IR } \\
\text { - } & \text { DDF/PF } \\
\text { - } & \text { Furans (furfuraldehyde) analysis (FFA) } \\
\text { - } & \text { DGA } \\
\text { - } & \text { Loss measurement }\end{array}$ & - & $\begin{array}{ll}- & \text { IR } \\
- & \text { PD } \\
- & \text { DGA }\end{array}$ & - \\
\hline Driver, Tap changer (D) & $\begin{array}{ll}- & \text { Temperature monitoring, } \\
\text { - } & \text { Infrared thermal image tests, } \\
\text { - } & \text { Contact resistance measurement } \\
\text { - } & \text { DGA }\end{array}$ & - & $\begin{array}{l}\text { - } \quad \text { Visual } \\
\text { - On-line monitor: motor } \\
\text { amps at } 2 \mathrm{kHz}, \\
\text { relay timing }\end{array}$ & $\begin{array}{ll}\text { - } & \text { Winding resistance } \\
\text { - } & \text { Turns ratio } \\
\text { - } & \text { DGA } \\
\text { - } & \text { Visual (internal after de-energization) }\end{array}$ \\
\hline Oil $(\mathrm{O})$ & $\begin{array}{ll}- & \text { DGA } \\
- & \text { On-line oil temperature measurement }\end{array}$ & $\begin{array}{ll}\text { - } & \text { Resistivity } \\
\text { - } & \text { DDF/PF } \\
\text { - } & \text { Electric or acoustic PD } \\
\text { - } & \text { DGA } \\
\text { - } & \text { IFT } \\
\text { - } & \text { Neutralization number } \\
\text { - } & \text { Polar compounds } \\
\text { - } & \text { Moisture in oil } \\
\text { - } & \text { Particle count } \\
\text { - } & \text { Breakdown voltage } \\
\text { - } & \text { Pump bearing monitor }\end{array}$ & - & $\begin{array}{ll}\text { - } & \text { Resistivity } \\
\text { - } & \text { DDF/PF } \\
\text { - } & \text { Electric or acoustic PD } \\
\text { - } & \text { DGA } \\
\text { - } & \text { IFT } \\
\text { - } & \text { Neutralization number } \\
\text { - } & \text { Polar compounds } \\
\text { - } & \text { Moisture in oil } \\
\text { - } & \text { Particle count } \\
\text { - } & \text { Breakdown voltage } \\
\text { - } & \text { Pump bearing monitor }\end{array}$ \\
\hline
\end{tabular}


Table 1. Cont.

\begin{tabular}{|c|c|c|c|c|}
\hline \multirow{2}{*}{ Components } & \multicolumn{4}{|c|}{ Nature of the Defect or Fault } \\
\hline & Thermal (T) & Dielectric (D) & Mechanical (M) & Contamination or aging $(\mathrm{C})$ \\
\hline Selector (S) & $\begin{array}{ll}\text { - } & \text { DC resistance } \\
\text { - } & \text { Electric or acoustic PD } \\
\text { - } & \text { On-line temperature differential }\end{array}$ & - & $\begin{array}{l}\text { - } \quad \text { Visual } \\
\text { - On-line monitor: motor } \\
\text { amps at } 2 \mathrm{kHz}, \\
\text { relay timing }\end{array}$ & $\begin{array}{ll}\text { - } & \text { Winding resistance } \\
\text { - } & \text { Turns ratio } \\
\text { - } & \text { DGA }\end{array}$ \\
\hline Tank and accessories (T) & $\begin{array}{ll}- & \text { DGA } \\
- & \text { Infrared scan of tank }\end{array}$ & - & $\begin{array}{ll}- & \text { Acoustic PD } \\
\text { - } & \text { DGA }\end{array}$ & $\begin{array}{ll}\text { - } & \text { Visual } \\
\text { - } & \text { DGA } \\
\text { - } & \text { Neutralization number } \\
\text { - } & \text { Dissolved metals }\end{array}$ \\
\hline $\begin{array}{l}\text { Winding, major insulation } \\
\text { and leads }(\mathrm{W})\end{array}$ & $\begin{array}{ll}- & \text { DC resistance } \\
- & \text { Electric or acoustic PD } \\
- & \left.\text { DGA (combustible gases and } \mathrm{CO}_{2}\right) \\
- & \text { DGA (consumption of oxygen) } \\
- & \text { Visual } \\
- & \text { Measure oil temperature } \\
- & \text { Furans (furfuraldehyde) analysis (FFA) }\end{array}$ & $\begin{array}{ll}\text { - } & \text { Electric or acoustic PD } \\
\text { - } & \text { Turns ratio } \\
\text { - } & \text { Magnetizing current } \\
\text { - } & \text { Winding resistance } \\
\text { - } & \text { FRA } \\
\text { - } & \text { DC resistance } \\
\text { - } & \text { DGA }\end{array}$ & $\begin{array}{ll}\text { - } & \text { Leakage reactance } \\
\text { - } & \text { Capacitance change } \\
\text { - } & \text { FRA/transfer } \\
& \text { function analysis } \\
\text { - } & \text { Vibration } \\
\text { - } & \text { DGA } \\
\text { - } & \text { Sound } \\
& \text { level measurement } \\
\text { - } & \text { visual }\end{array}$ & $\begin{array}{ll}- & \text { DDF/PF } \\
- & \text { RVM } \\
- & \text { Electric or acoustic PD } \\
- & \text { IR } \\
\text { - } & \text { IFT } \\
\text { - } & \text { Acid } \\
- & \text { Neutralization number } \\
- & \text { Oxidation stability } \\
- & \text { Sludge precipitation } \\
- & \text { Furans (furfuraldehyde) analysis (FFA) } \\
- & \text { Methanol content } \\
- & \text { DP } \\
- & \text { Moisture in oil } \\
- & \text { Water heat run } \\
- & \text { Moisture in paper (DRA) } \\
- & \text { DGA } \\
- & \text { Particle count } \\
- & \text { Breakdown voltage } \\
- & \text { Dissolved metals }\end{array}$ \\
\hline
\end{tabular}




\section{Conclusions}

This paper was authored by focusing on recent developments in electrical-based diagnostic techniques and to shed light on the opportunities provided for the diagnosis of faults in power transformers. A systematic review attempt determined that there are a variety of electrical-based diagnostic techniques available for monitoring power transformers, and many of them are moisture, temperature and aging dependant.

First, traditional methods have been discussed with currently available interpretation schemes. A number of modern diagnostic techniques were also presented in this paper and their usefulness and critical points highlighted. Some of them are standardised. None of the proposed method can be considered as the best diagnostic method. Since moisture content has a dominant influence on nearly all electrical-based diagnostic techniques for assessing the condition of insulation, combinations with physicochemical ones are sometimes essential for an accurate diagnosis.

Frequency domain spectroscopy measurements are preferred for quantitative assessments of the moisture in the insulation. However, despite being a promising area for research, the moisture and aging separation still constitute a challenging point. A number of attempts have been made by many authors in the last decade to solve this problem and this research is still ongoing.

Author Contributions: Both authors contributed equally to the reported research and writing of the paper.

Conflicts of Interest: The authors declare no conflict of interest.

\section{Abbreviations}

The following abbreviations are used in this manuscript:

$\begin{array}{ll}\text { CIGRE } & \text { International Council of Large Electric Systems } \\ \text { EDL } & \text { Electrical double layer } \\ \text { ECT } & \text { Electrostatic charging tendency } \\ \text { MST } & \text { Mini static tester } \\ \text { BTA } & \text { Benzotriazole } \\ \text { DLA } & \text { Dielectric loss angle } \\ \text { DDF } & \text { Dielectric dissipation factor } \\ \text { RVM } & \text { Recovery voltage measurement } \\ \text { RV } & \text { Recovery voltage } \\ \text { PDC } & \text { Polarization and depolarisation current } \\ \text { FDS } & \text { Frequency domain spectroscopy } \\ \text { DF } & \text { Dissipation factor } \\ \text { DFT } & \text { Digital Fourier transformation } \\ \text { PF } & \text { Power factor } \\ \text { IEEE } & \text { Institute of Electrical and Electronic Engineers } \\ \text { HV } & \text { High voltage } \\ \text { LV } & \text { Low voltage } \\ \text { IR } & \text { Insulation resistance } \\ \text { PI } & \text { Polarization index } \\ \text { FB } & \text { Frequency band } \\ \text { FRA } & \text { Frequency response analysis } \\ \text { FFA } & \text { Furfuraldehyde } \\ \text { SFRA } & \text { Sweep frequency response analysis } \\ \text { IFRA } & \text { Impulse frequency response analysis } \\ \text { TF } & \text { Transfer function } \\ \text { VF } & \text { Vector fitting } \\ \text { OLTC } & \text { On load tap changer } \\ \text { PD } & \text { Partial discharge } \\ \text { PRPD } & \text { Phase resolved partial discharge pattern } \\ \text { UHF } & \text { Ultra-high frequency } \\ \text { IEC } & \text { International Electrotechnical Commission } \\ \text { FFT } & \text { Fast Fourier transform } \\ \text { HFCT } & \text { High frequency current transformer } \\ \text { TTR } & \text { Transformer turn ratio } \\ & \end{array}$




\section{References}

1. Fofana, I.; Sabau, J. Application of Petroleum-Based Oil in Power Transformer. In Natural Gas Research Progress; David, N., Michel, T., Eds.; Nova Science Publishers, Inc.: Hauppauge, NY, USA, 2008; pp. $229-251$.

2. Guide for Transformer Maintenance; CIGRE WG A2.34; CIGRE: Paris, France, 2011; Volume 445, pp. 51-61.

3. N'Cho, J.S.; Fofana, I.; Hadjadj, Y.; Beroual, A. Review of the Physicochemical-Based Diagnostic Techniques for Assessing Insulation Condition in Aged Transformers. Energies 2016, 9, 367. [CrossRef]

4. Sierota, A.; Rungis, J. Electrical Insulating Oils, Part 1 Characterization and Pre-Treatment of New Transformer Oils. IEEE Electr. Insul. Mag. 1995, 11, 8-20. [CrossRef]

5. Standard for Insulating Liquids_Determination of the Breakdown Voltage at Power Frequency-Test Method; IEC 60156; International Electrotechnical Commission: Geneva, Switzerland, 1995.

6. Standard Test Method for Dielectric Breakdown Voltage of Insulating Liquids Using VDE Electrodes; ASTM D1816-12; ASTM International: West Conshohocken, PA, USA, 2012; Volume 10.3.

7. CIGRE Working Group A2-35. Experiences in Service with New Insulating Liquids; Cigré Report 436; CIGRE: Paris, France, 2010.

8. Standard Test Method for Dielectric Breakdown Voltage of Insulating Liquids Using Disk Electrodes; ASTM D877/D877M-13; ASTM International: West Conshohocken, PA, USA, 2013.

9. Crofts, D.W. The electrification phenomena in power transformers. IEEE Trans. Electr. Insul. 1988, 23, 137-146. [CrossRef]

10. Johnson, D.L. Insulating Oil Qualification and Acceptance Tests from a User's Perspective. In Electrical Insulating Oils; STP998; ASTM International: West Conshohocken, PA, USA, 1988.

11. Zhang, J.; Cao, L.J. The study on flow electrification of oil-cellulose insulating system in large power transformer. In Proceedings of the 1995 International Conference on Energy Management and Power Delivery, Singapore, 21-23 November 1995; Volume 1, pp. 416-427.

12. Mitchinson, P.M.; Lewin, P.L.; Strawbridge, B.D.; Jarman, P. Tracking and surface discharge at the oil-Pressboard interface. IEEE Electr. Insul. Mag. 2010, 26, 35-41. [CrossRef]

13. Metwally, I.A. Influence of solid insulating phase on streaming electrification of transformer oil. IEEE Trans. Dielectr. Electr. Insul. 1997, 4, 327-340. [CrossRef]

14. Mas, P.; Paillat, T.; Moreau, O.; Touchard, G. Flow electrification in power transformers: Temperature influence on space charge distribution and charge accumulation in pressboard. J. Electrost. 2001, 51-52, 488-493. [CrossRef]

15. Poovamma, P.K.; Jagadish, R.; Dwarakanath, K. Investigation on static electrification characteristics of transformer oil. J. Electrost. 1994, 33, 1-14. [CrossRef]

16. Lyon, D.J.; Melcher, J.R.; Zahn, M. Couette charger for measurement of equilibrium and energization flow electrification parameters: Application to transformer insulation. IEEE Trans. Electr. Insul. 1988, 23, 159-176. [CrossRef]

17. Radwan, R.M.; El-Dewieny, R.M.; Aish, T.D.; Metwally, I.A.H. Factors affecting transformer oil flow electrification in electric power apparatus. In Proceedings of the Annual Report Conference on Electrical Insulation and Dielectric Phenomena, Pocono Manor, PA, USA, 28-31 October 1990; pp. 642-647.

18. Bouslimi, Y.; Fofana, I.; Hemmatjou, H.; Volat, C. Static electrification assessment of transformer oils in the spinning disc system. In Proceedings of the 2010 International Conference on High Voltage Engineering and Application (ICHVE), New Orleans, LA, USA, 11-14 October 2010; pp. 337-340.

19. Shimizu, S.; Murata, H.; Honda, M. Electrostatics in Power Transformers. IEEE Trans. Power Appar. Syst. 1979, PAS-98, 1244-1250. [CrossRef]

20. Oommen, T.V.; Petrie, E.M. Eelectrostatic Charging Tendency of Transformer Oils. IEEE Trans. Power Appar. Syst. 1984, PAS-103, 1923-1931. [CrossRef]

21. Tanaka, T.; Yamada, N.; Yasojima, Y. Characteristics of streaming electrification in pressboard pipe and the influence of an external electric field. J. Electrost. 1985, 17, 215-234. [CrossRef]

22. Higaki, M.; Kako, Y.; Moriyama, M.; Hirano, M.; Hiraishi, K.; Kurita, K. Static Electrification and Partial Discharges Caused by Oil Flow in Forced Oil Cooled Core Type Transformers. IEEE Trans. Power Appar. Syst. 1979, PAS-98, 1259-1267. [CrossRef]

23. Okabe, S.; Kohtoh, M.; Amimoto, T. Investigation of electrostatic charging mechanism in aged oil-immersed transformers. IEEE Trans. Dielectr. Electr. Insul. 2010, 17, 287-293. [CrossRef] 
24. Okabe, S.; Kohtoh, M.; Amimoto, T. Diagnosis on increase in electrostatic charging tendency of mineral insulating oil for power transformers due to aging. IEEE Trans. Dielectr. Electr. Insul. 2010, 17, 953-963. [CrossRef]

25. Kanno, M.; Oota, N.; Suzuki, T.; Ishii, T. Changes in ECT and dielectric dissipation factor of insulating oils due to aging in oxygen. IEEE Trans. Dielectr. Electr. Insul. 2001, 8, 1048-1053. [CrossRef]

26. Fofana, I.; Bouslimi, Y.; Hemmatjou, H.; Volat, C.; Tahiri, K. Relationship between static electrification of transformer oils with turbidity and spectrophotometry measurements. Int. J. Electr. Power Energy Syst. 2014, 54, 38-44. [CrossRef]

27. Talhi, M.; Fofana, I.; Flazi, S. Impact of various stresses on the streaming electrification of transformer oil. J. Electrost. 2016, 79, 25-32. [CrossRef]

28. Oommen, T.V. Static electrification properties of transformer oil. IEEE Trans. Electr. Insul. 1988, 23, $123-128$. [CrossRef]

29. Bourgeois, A. Study of Flow Electrification Phenomena on High Power Transformers Pressboards. Ph.D. Thesis, Institut National Polytechnique de Grenoble-INPG, Grenoble, France, 2007.

30. Isaka, S.; Miyao, H.; Tsuchie, M.; Kobayashi, S.; Kobayashi, T.; Ono, T.; Ikeda, M.; Okubo, H. Investigation for standardization of electrostatic charging tendency measurement of transformer oil in Japan. In Proceedings of the 1999 IEEE 13th International Conference on Dielectric Liquids (ICDL '99), Nara, Japan, 20-25 July 1999; pp. 495-498.

31. Washabaugh, A.P.; Zahn, M. Flow electrification measurements of transformer insulation using a Couette flow facility. IEEE Trans. Dielectr. Electr. Insul. 1996, 3, 161-181. [CrossRef]

32. Kedzia, J. Investigation of transformer oil electrification in a spinning disk system. IEEE Trans. Dielectr. Electr. Insul. 1989, 24, 59-65. [CrossRef]

33. Static Electrification in Power Transformers; Gernaral Session, paper CE/SC 15/12-03; CIGRE: Paris, France, 1992.

34. Zelu, Y.; Paillat, T.; Morin, G.; Perrier, C.; Saravolac, M. Study on flow electrification hazards with ester oils. In Proceedings of the 2011 IEEE International Conference on Dielectric Liquids (ICDL), Trondheim, Norway, 26-30 June 2011; pp. 1-4.

35. Kobayashi, T.; Yajima, K.; Yamada, S.; Amimoto, T.; Hosokawa, N. Increase of static electrification in an aged oil-immersed transformer. Electr. Eng. Jpn. 2009, 167, 10-19. [CrossRef]

36. Ieda, M.; Okugo, H.; Tsukioka, H.; Goto, K.; Miyamoto, T.; Kohno, Y. Suppression of static electrification of insulating oil for large power transformers. IEEE Trans. Dielectr. Electr. Insul. 1988, 23, 153-157. [CrossRef]

37. Okabe, S.; Kohtoh, M.; Amimoto, T. Suppression of increase in electrostatic charging tendency of insulating oil by aging used for power transformer insulation. IEEE Trans. Dielectr. Electr. Insul. 2010, 17, $294-301$. [CrossRef]

38. Kawamura, T.K.T.; Amimoto, T.; Murakami, H.; Shirasaka, Y.; Ebisawa, Y. Failure Modes of Oil-Immersed Transformers Due to Static Electrification and Copper Sulphide Generation, and Suppressive Effect of BTA; CIGRE A2-206; CIGRE: Paris, France, 2008.

39. Paillat, T.; Touchard, G.; Bertrand, Y. "Capacitive Sensor" to Measure Flow Electrification and Prevent Electrostatic Hazards. Sensors 2012, 12, 14315-14326. [CrossRef] [PubMed]

40. Setayeshmehr, A.; Akbari, A.; Borsi, H.; Gockenbach, E. On-line monitoring and diagnoses of power transformer bushings. IEEE Trans. Dielectr. Electr. Insul. 2006, 13, 608-615. [CrossRef]

41. Riendeau, S.; Picher, P.; Léonard, F.; Gauvin, M.; Bertrand, H. On-line monitoring of transformer bushings using a new decentralized measurement system. In Proceedings of the Conference Record of the 2010 IEEE International Symposium on Electrical Insulation (ISEI), San Diego, CA, USA, 6-9 June 2010; pp. 1-5.

42. Reference Book on Insulating Liquids and Gases (RBILG) 391; Doble Engineering Company: Boston, MA, USA, 1993.

43. IEEE Guide for the Reclamation of Insulating Oil and Criteria for Its Use; IEEE Std C57.637-2015 (Revision of IEEE Std 637-1985); IEEE Standards Association: Piscataway, NJ, USA, 1985.

44. Transformer Diagnostics. In Facilities Instructions, Standards, and Techniques (FIST); Volume 3-31; United States Department of the Interior, Bureau of Reclamation: Washington, DC, USA, 2003; pp. 1-63.

45. IEEE Standard Test Code for Liquid-Immersed Distribution, Power, and Regulating Transformers; IEEE Std C57.12.90-2010 (Revision of IEEE Std C57.12.90-2006); IEEE Standards Association: Piscataway, NJ, USA, 2010; pp. 1-100. 
46. Winders, J. Power Transformers: Principles and Applications; CRC press: Boca Raton, FL, USA, 2002.

47. Wang, M.; Vandermaar, A.J.; Srivastava, K.D. Review of condition assessment of power transformers in service. IEEE Electr. Insul. Mag. 2002, 18, 12-25. [CrossRef]

48. IEEE Standard Test Code for Liquid-Immersed Distribution, Power, and Regulating Transformers and IEEE Guide for Short-Circuit Testing of Distribution and Power Transformers; ANSI/IEEE Std C57.12.90-1987; IEEE Standards Association: Piscataway, NJ, USA, 1988; p. 0_1.

49. Harlow, J.H. Electric Power Transformer Engineering, 3rd ed.; CRC Press: Boca Raton, FL, USA, 2012.

50. Supatra, A.B. The latest on-site non-destructive technique for insulation analysis of electrical power apparatus. In Proceedings of the the 2004 Weidmann-ACTI Annual Technical Conference, Sacramento, CA, USA, 8-10 November 2004.

51. Fofana, I.; Hemmatjou, H.; Farzaneh, M. Low Temperature and Moisture Effects on Polarization and Depolarization Currents of Oil-Paper Insulation. Electr. Power Syst. Res. 2010, 80, 91-97. [CrossRef]

52. Recommended Practice for Insulation Testing (2300 V and Above) with High Direct Voltage; IEEE Std 95-2002; IEEE Standards Association: Piscataway, NJ, USA, 2002.

53. Methods of Test for Volume Resistivity and Surface Resistivity of Solid Electrical Insulating Materials; IEC 60093; International Electrotechnical Commission: Geneva, Switzerland, 1980.

54. White, J. Transformers core-A different path to maintaining insulation systems. Electr. Today 2013, $26,42-44$.

55. IEC 60270. High-Voltage Test Techniques_Partial Discharge Measurements, 3rd ed.; International Electrotechnical Commission: Geneva, Switzerland, 2000.

56. Wu, M.; Cao, H.; Cao, J.; Nguyen, H.-L.; Gomes, J.B.; Krishnaswamy, S.P. An overview of state-of-the-art partial discharge analysis techniques for condition monitoring. Electr. Insul. Mag. IEEE 2015, 31, $22-35$. [CrossRef]

57. Fuhr, J. Procedure for identification and localization of dangerous PD sources in power transformers. IEEE Trans. Dielectr. Electr. Insul. 2005, 12, 1005-1014. [CrossRef]

58. Raymond, W.J.K.; Illias, H.A.; Bakar, A.H.A.; Mokhlis, H. Partial discharge classifications: Review of recent progress. Measurement 2015, 68, 164-181. [CrossRef]

59. Sokolov, V.; Mayakov, V.; Kuchinsky, G.; Golubev, A. On-Site Partial Discharge Measurement of Transformers. Available online: http://es.eaton.com/InsulGardSalesTool/Documentation/PD\% 20Transformer.pdf (accessed on 23 August 2016).

60. Feilat, E.A.; Metwally, I.A.; Al-Matri, S.; Al-Abri, A.S. Analysis of the Root Causes of Transformer Bushing Failures. Int. J. Comput. Electr. Autom. Control Inf. Eng. 2013, 7, 791-796.

61. Yaacob, M.; Alsaedi, M.; Rashed, J.; Dakhil, A.; Atyah, S. Review on partial discharge detection techniques related to high voltage power equipment using different sensors. Photonic Sens. 2014, 4, 325-337. [CrossRef]

62. Morshuis, P.H.F. Degradation of solid dielectrics due to internal partial discharge: Some thoughts on progress made and where to go now. IEEE Trans. Dielectr. Electr. Insul. 2005, 12, 905-913. [CrossRef]

63. Stone, G.C. Partial discharge diagnostics and electrical equipment insulation condition assessment. IEEE Trans. Dielectr. Electr. Insul. 2005, 12, 891-904. [CrossRef]

64. Niasar, M.G. Partial Discharge Signatures of Defects in Insulation Systems Consisting of Oil and Oil-impregnated Paper. Licentiate Thesis, KTH School of Electrical Engineering, Stockholm, Sweden, 2012.

65. Álvarez, F.; Garnacho, F.; Ortego, J.; Sánchez-Urán, M. Application of HFCT and UHF Sensors in On-Line Partial Discharge Measurements for Insulation Diagnosis of High Voltage Equipment. Sensors 2015, 15, 7360-7387. [CrossRef] [PubMed]

66. Schwarz, R.; Judendorfer, T.; Muhr, M. Review of Partial Discharge Monitoring techniques used in High Voltage Equipment. In Proceedings of the 2008 Annual Report Conference on Electrical Insulation and Dielectric Phenomena (CEIDP 2008), Quebec, QC, Canada, 26-29 October 2008; pp. 400-403.

67. Gautschi, D.; Weiers, T.; Buchs, G.; Wyss, S. Ultra High Frequency (UHF) Partial Discharge Detection for Power Transformers: Sensitivity Check on 800 MVA Power Transformers and First Field Experience; CIGRE A2-115; CIGRE: Paris, France, 2012.

68. Partial Discharge Detection System for GIS: Sensitivity Verification for the UHF Method and the Acoustic Method; CIGRE Task Force 15/33.03.05; ÉLECTRA No. 183; CIGRE: Paris, France; pp. 74-87.

69. Stone, G.C. Partial discharge. VII. Practical techniques for measuring PD in operating equipment. IEEE Electr. Insul. Mag. 1991, 7, 9-19. [CrossRef] 
70. Judd, M.D.; Li, Y.; Hunter, I.B.B. Partial discharge monitoring for power transformer using UHF sensors. Part 2: Field experience. IEEE Electr. Insul. Mag. 2005, 21, 5-13. [CrossRef]

71. Judd, M.D.; Li, Y.; Hunter, I.B.B. Partial discharge monitoring of power transformers using UHF sensors. Part I: Sensors and signal interpretation. IEEE Electr. Insul. Mag. 2005, 21, 5-14. [CrossRef]

72. Tenbohlen, S.; Denissov, D.; Hoek, S.M.; Markalous, S.M. Partial discharge measurement in the ultra high frequency (UHF) range. IEEE Trans. Dielectr. Electr. Insul. 2008, 15, 1544-1552. [CrossRef]

73. Coenen, S.; Tenbohlen, S.; Markalous, S.M.; Strehl, T. Sensitivity of UHF PD measurements in power transformers. IEEE Trans. Dielectr. Electr. Insul. 2008, 15, 1553-1558. [CrossRef]

74. Coenen, S.; Tenbohlen, S.; Markalous, S.M.; Strehl, T. Attenuation of UHF signals regarding the sensitivity verification for UHF PD measurements on power transformers. In Proceedings of the International Conference on Condition Monitoring and Diagnosis (CMD 2008), Beijing, China, 21-24 April 2008; pp. 1036-1039.

75. Su, C.Q. Electromagnetic Transients in Transformer and Rotating Machine Windings; IGI Global: Hershey, PA, USA, 2012.

76. Coenen, S.; Tenbohlen, S. Location of PD sources in power transformers by UHF and acoustic measurements. IEEE Trans. Dielectr. Electr. Insul. 2012, 19, 1934-1940. [CrossRef]

77. Judd, M.D. Experience with UHF partial discharge detection and location in power transformers. In Proceedings of the Electrical Insulation Conference (EIC), Annapolis, MD, USA, 5-8 June 2011; pp. 201-205.

78. Lazarevich, A.K. Partial Discharge Detection and Localization in High Voltage Transformers Using an Optical Acoustic Sensor. Master's Thesis, Faculty of the Virginia Polytechnic Institute and State University Blacksburg, VA, USA, 2003.

79. Lundgaard, L.E. Partial discharge. XIII. Acoustic partial discharge detection-fundamental considerations. IEEE Electr. Insul. Mag. 1992, 8, 25-31. [CrossRef]

80. Harrold, R.T. Acoustical Technology Applications in Electrical Insulation and Dielectrics. IEEE Trans. Electr. Insul. 1985, EI-20, 3-19. [CrossRef]

81. Harrold, R.T. Acoustic Waveguides for Sensing and Locating Electrical Discharges in High Voltage Power Transformers and Other Apparatus. IEEE Trans. Power Appar. Syst. 1979, PAS-98, 449-457. [CrossRef]

82. Liu, H.-L. Acoustic partial discharge localization methodology in power transformers employing the quantum genetic algorithm. Appl. Acoust. 2016, 102, 71-78. [CrossRef]

83. Markalous, S.; Tenbohlen, S.; Feser, K. Detection and location of partial discharges in power transformers using acoustic and electromagnetic signals. IEEE Trans. Dielectr. Electr. Insul. 2008, 15, 1576-1583. [CrossRef]

84. Veloso, G.F.C.; da Silva, L.E.B.; Lambert-Torres, G.; Pinto, J.O.P. Localization of Partial Discharges in Transformers by the Analysis of the Acoustic Emission. In Proceedings of the 2006 IEEE International Symposium on Industrial Electronics, Montreal, QC, Canada, 9-13 June 2006; pp. 537-541.

85. Muhr, M.; Strehl, T.; Gulski, E.; Feser, K.; Gockenbach, E.; Hauschild, W.; Lemke, E. Sensors and Sensing Used for Non-Conventional PD Detection; CIGRE Working Group: Paris, France, 2006; Volume D1-102.

86. Hekmati, A. A novel acoustic method of partial discharge allocation considering structure-borne waves. Int. J. Electr. Power Energy Syst. 2016, 77, 250-255. [CrossRef]

87. Hekmati, A. Proposed method of partial discharge allocation with acoustic emission sensors within power transformers. Appl. Acoust. 2015, 100, 26-33. [CrossRef]

88. Danouj, B.; Tahan, A.A.; David, E. Using a new generation of piezoelectric sensors for partial discharge detection. Measurement 2013, 46, 660-666. [CrossRef]

89. Posada-Roman, J.; Garcia-Souto, J.A.; Rubio-Serrano, J. Fiber Optic Sensor for Acoustic Detection of Partial Discharges in Oil-Paper Insulated Electrical Systems. Sensors 2012, 12, 4793-4802. [CrossRef] [PubMed]

90. Wang, X.; Li, B.; Roman, H.T.; Russo, O.L.; Chin, K.; Farmer, K.R. Acousto-optical PD detection for transformers. IEEE Trans. Power Deliv. 2006, 21, 1068-1073. [CrossRef]

91. MacAlpine, M.; Zhao, Z.; Demokan, M.S. Development of a fibre-optic sensor for partial discharges in oil-filled power transformers. Electr. Power Syst. Res. 2002, 63, 27-36. [CrossRef]

92. Deng, J.; Xiao, H.; Huo, W.; Luo, M.; May, R.; Wang, A.; Liu, Y. Optical fiber sensor-based detection of partial discharges in power transformers. Optics Laser Technol. 2001, 33, 305-311. [CrossRef]

93. Yin, S.; Ruffin, P.B.; Yu, F.T.S. Fiber Optic Sensors, 2nd ed.; CRC Press: Boca Raton, FL, USA, 2008.

94. Chakravorti, S.; Dey, D.; Chatterjee, B. Recent Trends in the Condition Monitoring of Transformers: Theory, Implementation and Analysis; Springer: London, UK, 2013. 
95. Bakar, N.A.; Abu-Siada, A.; Islam, S. A review of dissolved gas analysis measurement and interpretation techniques. IEEE Electr. Insul. Mag. 2014, 30, 39-49. [CrossRef]

96. Duval, M.; de Pabla, A. Interpretation of gas-in-oil analysis using new IEC publication 60599 and IEC TC 10 databases. IEEE Electr. Insul. Mag. 2001, 17, 31-41. [CrossRef]

97. Frequency Response Analysis on Winding Deformation of Power Transformers; DL/T 911-2004; National Development and Reform Commission of the People's Republic of China: Beijing, China, 2005.

98. Cigré WG A2/26. Mechanical condition assessment of transformer windings using Frequency Response Analysis (FRA); CIGRE: Paris, France, 2008.

99. Power Transformers -Part 18: Measurement of Frequency Response; IEC 60076-18; International Electrotechnical Commission: Geneva, Switzerland, 2012.

100. IEEE Guide for the Application and Interpretation of Frequency Response Analysis for Oil-Immersed Transformers; IEEE Std C57.149; IEEE Standards Association: Piscataway, NJ, USA, 2012.

101. The Short-Circuit Performance of Power Transformers; CIGRE WG 12.19; CIGRE Technical Brochure 209; CIGRE: Paris, France, 2002.

102. Sweetser, C.; McGrail, T. Sweep Frequency Response Analysis Transformer Applications; Doble Engineering Company: Watertown, MA, USA, 2003.

103. Mechanical-Condition Assessment of Transformer Windings Using Frequency Response Analysis (ERA); CIGRE WG A2.26.; CIGRE Report 342; CIGRE: Paris, France, 2008.

104. Bagheri, M.; Phung, B.T.; Blackburn, T. Influence of temperature and moisture content on frequency response analysis of transformer winding. IEEE Trans. Dielectr. Electr. Insul. 2014, 21, 1393-1404. [CrossRef]

105. Karimifard, P.; Gharehpetian, G.B.; Tenhohlen, S. Localization of winding radial deformation and determination of deformation extend using vector fitting-based estimated transfer function. Eur. Trans. Electr. Power 2009, 19, 749-762. [CrossRef]

106. Mohamed, Y.R.; Meghnefi, F.; Fofana, I. Frequency Response Analyses via Rational Function Fitting. In Proceedings of the 2012 IEEE Annual Conference on Electrical Insulation and Dielectric Phenomena (CEIDP), Montreal, QC, Canada, 14-17 October 2012.

107. Bigdeli, M.; Vakilian, M.; Rahimpour, E. A New Method for Detection and Evaluation of Winding Mechanical Faults in Transformer through Transfer Function Measurements. Adv. Electr. Comput. Eng. 2011, 11, $23-30$. [CrossRef]

108. Behjat, V.; Vahedi, A.; Setayeshmehr, A.; Borsi, H.; Gockenbach, E. Diagnosing Shorted Turns on the Windings of Power Transformers Based Upon Online FRA Using Capacitive and Inductive Couplings. IEEE Trans. Power Deliv. 2011, 26, 2123-2133. [CrossRef]

109. Jonscher, K. Dielectric Polarisation/Depolarisation in Solids; Chelsea Dielectric Press: London, UK, 1984.

110. Zaengl, W.S. Application of Dielectric Spectroscopy in Time and Frequency Domain for HV Power Equipment. IEEE Electr. Insul. Mag. 2003, 19, 9-22. [CrossRef]

111. CIGRE Task Force 15.01.09. Dielectric Response Methods for Diagnostics of Power Transformers; Cigre brochure 254, Electra 202; CIGRE: Paris, France, 2003; pp. 25-36.

112. Saha, T.K. Review of Modern Diagnostic Techniques for Assessing Insulation Condition in Aged Transformers. IEEE Trans. Dielectr. Electr. Insul. 2003, 10, 903-917. [CrossRef]

113. Zaengl, W.S. Dielectric Spectroscopy in Time and Frequency Domain for HV Power Equipment, Part I: Theoretical Considerations. IEEE Electr. Insul. Mag. 2003, 19, 5-19. [CrossRef]

114. Seytashmehr, A.; Fofana, I.; Eichler, C.; Akbari, A.; Borsi, H.; Gockenbach, E. Dielectric Spectroscopic Measurements on Transformer Oil-Paper Insulation under Controlled Laboratory Conditions. IEEE Trans. Dielectr. Electr. Insul. 2008, 15, 1100-1111. [CrossRef]

115. Fofana, I.; Hemmatjou, H.; Meghnefi, F. Effect of Thermal Transient on the Polarization and Depolarization Current Measurements of Oil-Paper Insulation. IEEE Trans. Dielectr. Electr. Insul. 2011, 18, 513-520. [CrossRef]

116. Liao, R.; Hao, J.; Chen, G.; Yang, L. Quantitative analysis of ageing condition of oil-paper insulation by frequency domain spectroscopy. IEEE Trans. Dielectr. Electr. Insul. 2012, 19, 821-830. [CrossRef]

117. Suriyah-Jaya, M.; Leibfried, T. Accelerating Dielectric Response Measurements on Power Transformers-Part II: A Regression Approach. IEEE Trans. Power Deliv. 2014, 29, 2095-2100. [CrossRef]

118. Yousof, M.F.M.; Ekanayake, C.; Saha, T.K. Examining the ageing of transformer insulation using FRA and FDS techniques. IEEE Trans. Dielectr. Electr. Insul. 2015, 22, 1258-1265. [CrossRef] 
119. Blennow, J.; Ekanayake, C.; Walczak, K.; Garcia, B.; Gubanski, S.M. Field experiences with measurements of dielectric response in frequency domain for power transformer diagnostics. IEEE Trans. Power Deliv. 2006, 21, 681-688. [CrossRef]

120. Pradhan, M.K.; Yew, K.J.H. Experimental investigation of insulation parameters affecting power transformer condition assessment using frequency domain spectroscopy. IEEE Trans. Dielectr. Electr. Insul. 2012, 19, 1851-1859. [CrossRef]

121. Van Bolhuis, P. Applicability of Recovery Voltage and on-line Partial Discharge Measurements for Condition Assessment of High Voltage Power Transformers; Optima Grafische Communicatie: Rotterdam, The Netherlands, 2002; pp. 105-153.

122. Kachler, A.J.; Baehr, R.; Zaengl, W.S.; Breitenbauch, B.; Sundermann, U. Kritische Anmerkungen zur Feuchtigkeitsbestimmung von Transformatoren mit der "Recovery-Voltage-Methode". Elektrizitätswirtschaft 1996, 95, 1238-1245. (In German)

123. Kachler, A.J. Ageing and Moisture Determination in Power Transformer Insulation Systems. Contradiction of RVM Methodology, Effects of Geometry and Ion Conductivity. In Proceedings of the 2nd International Workshop on Transformers, Lodz, Poland, 24-27 November 1999.

124. Saha, T.K.; Purkait, P. Investigations of temperature effects on the dielectric response measurements of transformer oil-paper insulation system. IEEE Trans. Power Deliv. 2008, 23, 252-260. [CrossRef]

125. Jaya, M.; Geißler, D.; Leibfried, T. Accelerating dielectric response measurements on power transformers-Part I: A frequency domain approach. IEEE Trans. Power Deliv. 2013, 28, 1469-1473. [CrossRef]

126. Jaya, M.; Leibfried, T. Accelerating Dielectric Response Measurements on Power Transformers-Part II: A Regression Approach. IEEE Trans. Power Deliv. 2014, 29, 2095-2100. [CrossRef]

127. Shayegani, A.A.; Gockenbach, E.; Borsi, H.; Mohseni, H. Investigation on the transformation of time domain spectroscopy data to frequency domain data for impregnated pressboard to reduce measurement time. Electr. Eng. 2006, 89, 11-20. [CrossRef]

128. Farahani, M.; Borsi, H.; Gockenbach, E. Dielectric Response Studies on Insulating System of High Voltage Rotating Machines. IEEE Trans. Dielectr. Electr. Insul. 2006, 13, 383-393. [CrossRef]

129. Birlasekaran, S.; Yu, X. Relaxation Studies on Power Equipment. IEEE Trans. Dielectr. Electr. Insul. 2003, 10, 1061-1077. [CrossRef]

130. Dong, M.; Ren, M.; Wen, F.; Zhang, C.; Liu, J.; Sumereder, C.; Muhr, M. Explanation and analysis of oil-paper insulation based on frequency-domain dielectric spectroscopy. IEEE Trans. Dielectr. Electr. Insul. 2015, 22, 2684-2693.

131. Hadjadj, Y.; Meghnefi, F.; Fofana, I.; Ezzaidi, H. On the Feasibility of Using Poles Computed from Frequency Domain Spectroscopy to Assess Oil Impregnated Paper Insulation Conditions. Energies 2013, 6, 2204-2220. [CrossRef]

132. Saha, T.K.; Purkait, P. Understanding the impacts of moisture and thermal aging on transformer's insulation by dielectric response and molecular weight measurements. IEEE Trans. Dielectr. Electr. Insul. 2008, 15, 568-582. [CrossRef]

133. Yao, Z.T.; Saha, T.K. Separation of Ageing and Moisture Impacts on Transformer Insulation Degradation by Polarisation Measurements; CIGRE: Paris, France, 2002; pp. 15-304.

134. Betie, A.; Meghnefi, F.; Fofana, I.; Yeo, Z.; Ezzaidi, H. Neural network approach to separate aging and moisture from the dielectric response of oil impregnated paper insulation. IEEE Trans. Dielectr. Electr. Insul. 2015, 22, 2176-2184. [CrossRef]

135. Tang, W.H.; Wu, Q.H. Condition Monitoring and Assessment of Power Transformers Using Computational Intelligence; Springer: London, UK, 2011.

136. Tenbohlen, S.; Stirl, T.; Bastos, G.; Baldauf, J.; Mayer, P.; Stach, M.; Breitenbauch, B.; Huber, R. Experience-Based Evaluation of Economic Benefits of On-line Monitoring Systems for Power Transformers; CIGRE Session 2002; Paris, France, 2002; pp. 12-110.

137. CIGRE WG 12.18 Life Management of Transformers. Guidelines for Life Management Techniques for Power Transformers. Draft Final Report Rev. 2, 22 June 2002. Available online: http:/ / www.buenomak.com.br/ publicacoes/pdf/TRANSFdePOTEN-2002_life_management_techniques.pdf (accessed on 9 May 2016).

(C) 2016 by the authors; licensee MDPI, Basel, Switzerland. This article is an open access article distributed under the terms and conditions of the Creative Commons Attribution (CC-BY) license (http://creativecommons.org/licenses/by/4.0/). 